\title{
Aperiodic mineral structures
}

\author{
L. BINDI ${ }^{1}$ and G. CHAPUIS ${ }^{2}$ \\ ${ }^{1}$ Dipartimento di Scienze della Terra, Università di Firenze, \\ Via La Pira 4, I-50121 Firenze, Italy \\ ${ }^{2}$ Laboratoire de Cristallographie, École Polytechnique Fédérale de Lausanne, \\ CH-1015 Lausanne, Switzerland
}

\begin{abstract}
The three-dimensional periodic nature of crystalline structures was so strongly anchored in the minds of scientists that the numerous indications that seemed to question this model struggled to acquire the status of validity. The discovery of aperiodic crystals, a generic term including modulated, composite and quasicrystal structures, started in the 1970s with the discovery of incommensurately modulated structures and the presence of satellite reflections surrounding the main reflections in the diffraction patterns. The need to use additional integers to index such diffractograms was soon adopted and theoretical considerations showed that any crystal structure requiring more than three integers to index its diffraction pattern could be described as a periodic object in a higher dimensional space, i.e. superspace, with dimension equal to the number of required integers. The structure observed in physical space is thus a three-dimensional intersection of the structure described as periodic in superspace.

Once the symmetry properties of aperiodic crystals were established, the superspace theory was soon adopted in order to describe numerous examples of incommensurate crystal structures from natural and synthetic organic and inorganic compounds even to proteins. Aperiodic crystals thus exhibit perfect atomic structures with long-range order, but without any three-dimensional translational symmetry.

The discovery of modulated structures was soon followed by the discovery of composite structures consisting of structural entities with partly independent translations and finally by the discovery of quasicrystals.

In recent years, the use of CCD and imaging plate systems improved considerably the sensitivity of data collection for aperiodic structures and in particular modulated structures and, therefore, there was a need for further improvement of the methods. Today, several computer programs are able to solve and refine incommensurately modulated structures using the superspace approach.

In nature, it is uncommon to find minerals which have strong and sharp incommensurate satellites that could be used for a higher dimensional refinement. Here we describe several cases of aperiodic minerals (natrite, calaverite, melilite, fresnoite, pearceite-polybasite, cylindrite) including the first examples of natural and stable quasicrystalline structures (icosahedrite and decagonite) which settle beyond doubt any questions which remain about the long-term stability of quasicrystals.
\end{abstract}

\section{Is the law of rational indices of general validity? Background information from the history of crystallography}

The discovery of X-ray diffraction in 1912 followed by the first descriptions of simple crystalline structures by the Braggs in 1914 were at the origin of a new paradigm in the field of physics and chemistry in particular concerning the structural properties of 
matter. The award of the Nobel prize in physics to Max von Laue in 1914 for the discovery of X-ray diffraction by crystals followed a year later by another such prize to W. Henry and W. Lawrence Bragg for the analysis of crystal structures by means of $\mathrm{X}$-rays, is direct proof of the tremendous significance and impact of diffraction on the scientific community. The elegant description of crystalline structures on the basis of a three-dimensional periodical array of atoms was so convincing at that time that no scientist dared to question this seemingly universal model.

Note that the first analyses of crystal structures, based on diffraction experiments, benefitted enormously from the pioneering works of mineralogists like Haüy, Bravais and many others. The law of rational indices and the notions of direct and reciprocal lattice vectors were already well known as well as the fact that crystalline faces were parallel to lattice planes and normal to reciprocal lattice vectors (e.g. Rigault, 1999). Therefore, the three (usually small) indices used to characterize any single crystalline face could easily be associated with the same three indices characterizing each single spot on the newly discovered X-ray diffraction (XRD) patterns. Obviously, these three indices were considered to be direct proof of the three-dimensional periodic character of crystalline matter.

And yet, by the beginning of the $20^{\text {th }}$ century, mineralogists had already presented some striking observations pertaining to the general validity of the law of rational indices. We shall follow the evolution of these observations with the example of the mineral calaverite $\left(\mathrm{Au}_{1-x} \mathrm{Ag}_{x} \mathrm{Te}_{2}\right.$, with $\left.0 \leqslant x \leqslant 0.33\right)$ over a period of nearly one century. First Penfield and Ford (1902) pointed to the difficulties involved in indexing faces with small rational indices. Later Smith (1903) used a collection of 49 different samples and attempted to find a plausible model for indexing the crystal faces. The best he could propose was to admit the existence of three interpenetrating structures, two of them triclinic and one monoclinic! Faced with this awkward interpretation, the author proposed for the first time the idea of incommensurability in crystals.

Some 30 years later, Goldschmidt, Palache and Peacock (1931, labelled hereafter as GPP) investigated a collection of 105 different samples originating from different continents with high-precision goniometry and here again no simple indexing model could be proposed. The authors concluded that "the law of rational indices is not of general validity" and that crystalline faces might have irrational indices. Of course, from our $21^{\text {st }}$ century point of view they were right but the three-dimensional periodic nature of crystals was so deep-rooted in the minds of scientists that the conclusions of their study had to wait another half century before being fully recognized! It is worth looking at the gnomonic projection published by GPP in order to see how close they were to a breakthrough in the interpretation of their data. Figure 1 is an augmented representation of the original figure. It can be interpreted as a representation of the structure in reciprocal space. The dark grid linking the open points indicated by letters is from the original figure. To each node of the grid we can thus assign three indices (the first three integers). For the remaining grey points, we observe that all of them are located on a series of parallel lines indicated by the vector, $\mathbf{q}$, represented on the figure, each of them crossing the grid points mentioned above. Moreover, each one is located on integer multiples of the same vector. Thus, it seems natural to reinterpret each point 


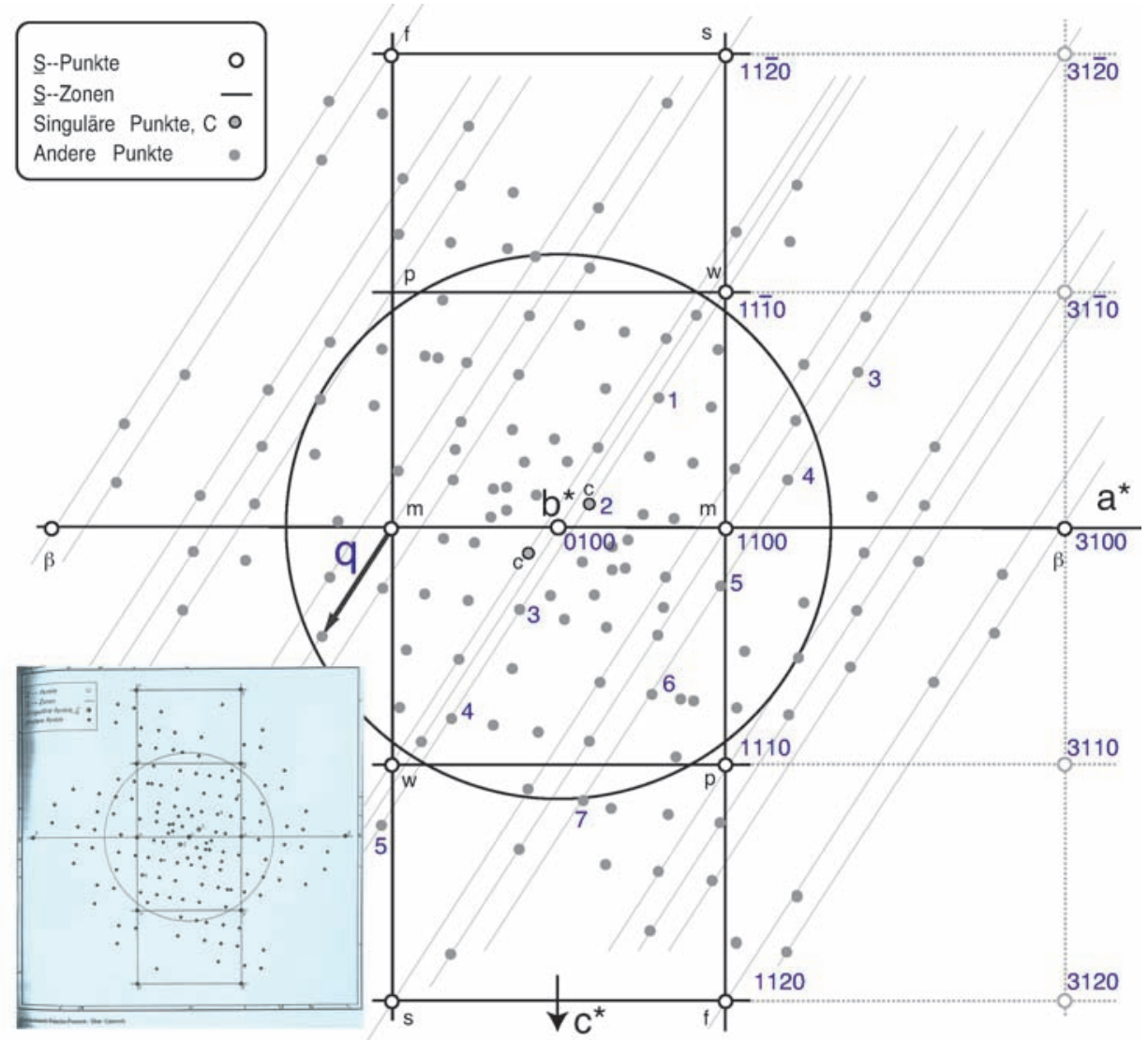

Fig. 1. Gnomonic projection of the crystal forms of calaverite according to Goldschmidt et al. (1931). The inset illustrates the original figure whereas the main figure is reinterpreted by indicating the three reciprocal basis vectors $\mathbf{a}^{*}, \mathbf{b}^{*}$ and $\mathbf{c}^{*}$ and introducing an additional vector $\mathbf{q}$ allowing the indexing of all the forms in terms of four indices.

of the gnomonic projection in terms of three indices provided by the lattice point containing the parallel line and a fourth index giving the multiple of the vector, $\mathbf{q}$. Thus each point is characterized uniquely by four indices. On Fig. 1 for example, points with indices $11 \overline{1} 0,11 \overline{1} 1 \ldots 11 \overline{1} 5$ are indicated. (Note that the four indices used here are not to be confused with the indexing with four integers used for trigonal and hexagonal crystals!). The addition of a fourth reciprocal lattice vector, q, prevents us from using any irrational number to fully index the gnomonic projection. We shall see below how we can deal with the additional vector, $\mathbf{q}$.

The understanding of the morphology of calaverite had to wait nearly half a century when Janner and Dam (1989) published a new and more convincing indexing of the calaverite forms (Fig. 2) based on the GPP data. All the faces could be indexed in terms of a twin and the four indices presented above. 
The need for and the significance of using additional indices was only understood later when diffraction patterns of mainly single crystals started to appear. It is worth citing the work of Korekawa (1967) who published his 'Habilitationsschrift' in German on the theory of satellite reflections. At that time, a few examples of single-crystal diffraction patterns could only meaningfully be indexed by using four indices, similar to the indexation of the calaverite forms based on GPP data. Soon the expression 'satellites' was adopted for those reflections with the fourth index different from 0 . In other words, all those equidistant reflections located on a straight line crossing a main reflection located at the intersection of a three-dimensional reciprocal lattice were called 'satellite' reflections. In his work, Korekawa (1967) did show how a periodical perturbation or modulation in addition to the independent three-dimensional lattice periodicity could lead to the formation of satellite reflections, hence the name 'modulated structures' to characterize them. He studied various longitudinal and transversal periodic distortions as well as density variations and showed their effect on the diffraction patterns. In particular, he could explain the formation of satellite reflections in labradorite, a variety of the mineral anorthite, which will be mentioned below.

Unfortunately, the work of Korekawa (1967) did not have the expected impact in structural sciences probably because of its lack of symmetry treatment for modulated structures. Symmetry is so fundamental for the description of periodic structures that any theory of modulated structure has to include its symmetry properties. The first treatment of the symmetry of modulated structures was by P.M. de Wolff who
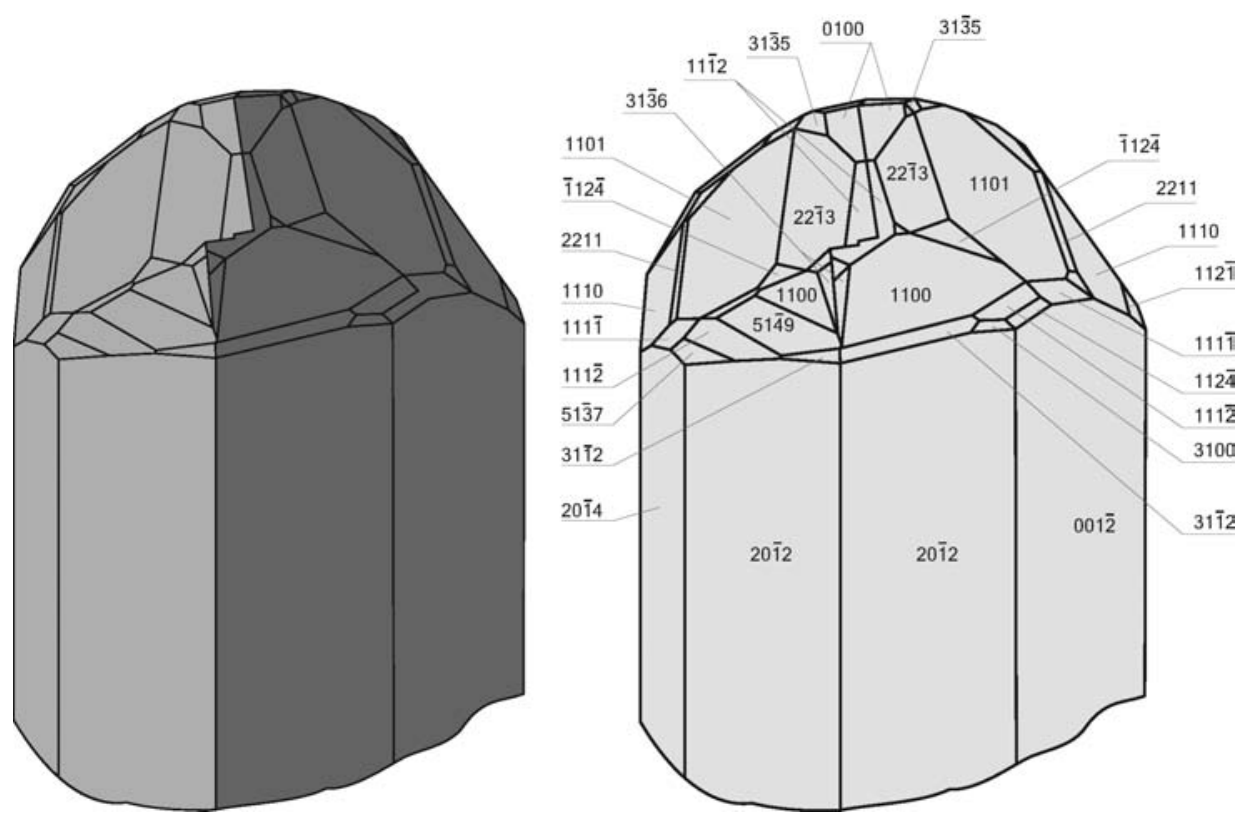

Fig. 2. A reinterpretation of the calaverite forms originally published by Goldschmidt et al. (1931). All the faces of the twin indicated on the left are indexed with four indices (right). 
published in 1974 the first elements of a symmetry theory with the example of the modulated structure of $\gamma-\mathrm{Na}_{2} \mathrm{CO}_{3}$. This work is at the basis of the theory, which was later called 'superspace', a higher dimensional space, which is particularly convenient to describe modulated structures. A modulated structure is periodic in superspace and its three-dimensional section is the real-space representation of its structure. The concept of superspace will be described in more detail below.

Once structural scientists realised that the paradigm of purely three-dimensional structures had to be abandoned, the path for new discoveries on the complexity of materials was opened. In 1981, Makovicky and Hyde published an important study of non-commensurate (misfit) layer structures describing numerous examples of mineral structures consisting of two components each showing no commensurability in the periodicities of the structural components parallel to the layers but strict periodicity normal to the layers. Structures with similar characteristics are currently classified under the name 'composite' structures. It was later realised that composite structures could also be very conveniently described in terms of the superspace concept.

The publication with the largest impact on structural sciences relates to the discovery of "quasicrystals" by Shechtman, Blech, Gratias and Cahn (1984). The authors discovered the existence of stable metallic phases with long-range orientational order but without any translational symmetry. Here again, the diffraction patterns could only meaningfully be indexed by using up to six (usually small) integers. This discovery laid the basis for a new research paradigm and established definitely the superspace concept as the tool of choice to describe 'aperiodic' structures, a generic term combining modulated, composite and quasicrystalline structures.

\section{An elementary introduction to the concept of superspace and redefinition of a crystal}

In order to gain some insight into the concept of superspace, let us consider the indexation of the series of points located on the gnomonic projection represented in Fig. 1. We have seen that the gnomonic projection is a faithful representation of the reciprocal space similar to a reciprocal layer of a diffraction pattern. Therefore, any point can be represented by a reciprocal lattice vector, $\mathbf{H}$ (equation 1 ) in terms of the basis vectors, $\mathbf{a}_{i}^{*}(i=1,2,3)$ and the modulation vector, $\mathbf{q}$, with integers $h_{i}$ and $m$ :

$$
\mathbf{H}=h_{1} \mathbf{a}_{1}^{*}+h_{2} \mathbf{a}_{2}^{*}+h_{3} \mathbf{a}_{3}^{*}+m \mathbf{q}
$$

Our next task is to represent our reciprocal space in higher dimension, i.e. in superspace, in order to accommodate the additional reciprocal lattice vector, $\mathbf{q}$. This can be done according to the recipe illustrated in Fig. 3. The basic principle of this extension is to consider that the satellite reflections observed in diffraction patterns result from a projection of a higher-dimensional space onto the physical space. Let us deal first with the vector $\mathbf{a}_{S 4}^{*}$ defined in superspace. It has a component $\mathbf{q}$ in the physical space $R^{*}$ (also called 'external' or 'parallel space') and the unit vector, $\mathbf{e}_{4}^{*}$ in the space normal to it, which is sometimes called 'internal space' or 'perpendicular space'. The 
modulation vector $\mathbf{q}$ is usually expressed in terms of the reciprocal lattice vector:

$$
\mathbf{q}=\alpha \mathbf{a}_{1}^{*}+\beta \mathbf{a}_{2}^{*}+\gamma \mathbf{a}_{3}^{*}
$$

Thus $\mathbf{a}_{S 4}^{*}$ can be expressed in the two-component form given in equation 4 . The expression for the other components $\mathbf{a}_{S i}^{*}$ (where $\left.i=1,2,3\right)$ is somewhat simpler, only the external component is present whereas the internal component is nil. This is illustrated in Fig. 3 for the vectors $\mathbf{a}_{S 1}^{*}$ and $\mathbf{a}_{1}^{*}$ which are parallel and have the same length.

Once the reciprocal lattice vectors are defined in superspace, the corresponding dual vectors in superspace can be derived. Similar to the classical case in $3 \mathrm{D}$, we can use the same relation between direct and reciprocal lattice vectors. The scalar product of direct and reciprocal lattice vectors is given by the Kronecker symbol $\delta_{i j}$, i.e. $\delta=1$ if $i$ and $j$ are identical and 0 otherwise. We have to generalize the scalar product in order to include both external and internal components of the vectors (the indices for the external components are omitted):

$$
\mathbf{u}_{S} \cdot \mathbf{v}_{S}=\mathbf{u} \cdot \mathbf{v}+u_{I} v_{I} \text { for }\left(\mathbf{u}, u_{I}\right) \text { and }\left(\mathbf{v}, v_{I}\right)
$$

The definition of the lattice vectors in superspace is thus given by equation 4 . Each vector consists of two components given in parentheses, the external and the internal components, respectively.

$$
\left.\begin{array}{l}
\mathbf{a}_{S 1}^{*}=\left(\mathbf{a}_{1}^{*}, 0\right) \\
\mathbf{a}_{S 2}^{*}=\left(\mathbf{a}_{2}^{*}, 0\right) \\
\mathbf{a}_{S 3}^{*}=\left(\mathbf{a}_{3}^{*}, 0\right) \\
\mathbf{a}_{S 4}^{*}=(\mathbf{q}, 1)
\end{array}\right\} \rightarrow \mathbf{a}_{S i} \cdot \mathbf{a}_{S j}^{*}=\delta_{i j} \rightarrow\left\{\begin{array}{l}
\mathbf{a}_{S 1}=\left(\mathbf{a}_{1},-\mathbf{q} \cdot \mathbf{a}_{1}\right) \\
\mathbf{a}_{S 2}=\left(\mathbf{a}_{2},-\mathbf{q} \cdot \mathbf{a}_{2}\right) \\
\mathbf{a}_{S 3}=\left(\mathbf{a}_{3},-\mathbf{q} \cdot \mathbf{a}_{3}\right) \\
\mathbf{a}_{S 4}=(0,1)
\end{array}\right.
$$

For simplification, the above definition is limited to four dimensions. It is straightforward to include additional dimensions with modulation vectors $\mathbf{q}_{1}, \mathbf{q}_{2}$, etc. and to derive the corresponding superspace components.

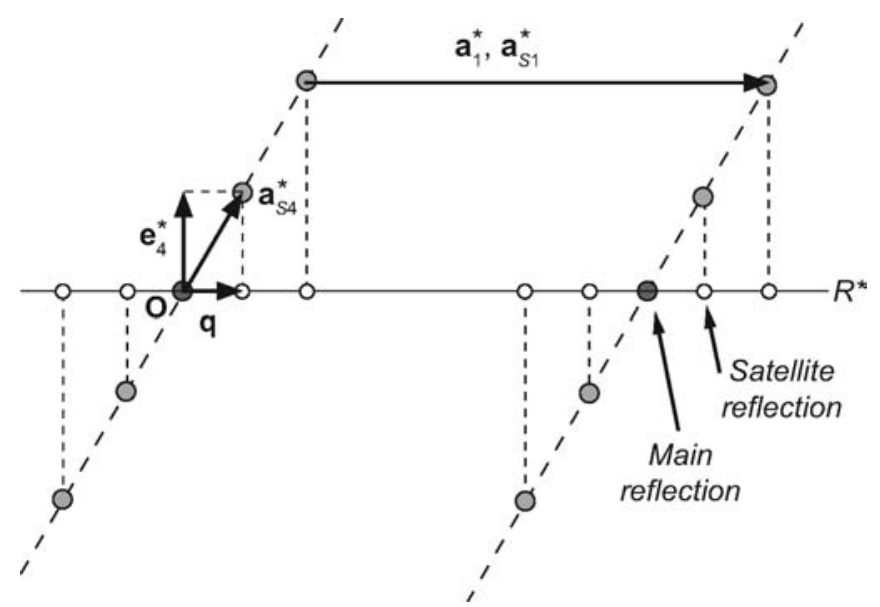

Fig. 3. Representation of main and satellite reflections in superspace. See text for explanations. 
The immediate problem we are facing when dealing with the description of a structure in higher dimensional space concerns its representation. We know perfectly well how to reconstruct a three-dimensional object out of a series of two-dimensional sections. Moreover we can minimize the number of sections provided an optimal selection of planes. For example, a single 2D section is sufficient to represent any close-packed $3 \mathrm{D}$ structure. We shall do the same for the representation of a structure in superspace. We shall describe and analyse it in terms of a series of two-dimensional sections. Figure 4 illustrates the representation of a modulated structure with a transverse displacement wave. On the left a structure is represented by a two-dimensional array of points subject to a transverse modulation along $\mathbf{a}_{2}$ with a wavelength, $\lambda$, which is not generally commensurate with the periodicity of $\mathbf{a}_{2}$. The structure is periodic along $\mathbf{a}_{1}$, however. The $\left(\mathbf{a}_{S 2}, \mathbf{a}_{S 4}\right)$ section is represented on the right. According to the definitions given in equation 4, the basis vector in superspace $\mathbf{a}_{S 2}$ consists of the two components $\mathbf{a}_{2}$ and $-\mathbf{q} \cdot \mathbf{a}_{2}$. The component $\mathbf{a}_{S 4}$ is normal to $\mathbf{a}_{2}$ according to the same definitions. In our representation, a string, a sinusoidal wave in the present example, which is periodically repeating, represents each atom. The $2 \mathrm{D}$ unit cell is illustrated in grey in the figure. The structure of the real crystal can be seen on the right figure from the intersection of the periodic array of sinusoidal waves along $\mathbf{a}_{2}$. The series of intersecting points are not periodic and the departure of $x_{2}$ from the average $\bar{x}_{2}$ varies along $\mathbf{a}_{2}$. We have thus verified that the real crystal is identical to the transverse modulation represented on the left. The $\left(\mathbf{a}_{S 1}, \mathbf{a}_{S 4}\right)$ section is not represented but its construction is straightforward: a straight line located at $\bar{x}_{\mathrm{i}}$ would replace the sinusoidal wave and its intersection would be periodic.

Since the discovery of modulated crystals, many different types of periodic modulation functions have been introduced to improve their descriptions. Modulated structures rarely exhibit a purely sinusoidal wave. In most cases, the periodic perturbation can be better approximated by a series of harmonic terms if the resolution of the data permits it. Other perturbation functions have been proposed, e.g. step functions or saw tooth functions as illustrated in Fig. 5 (left). In the case of defects for example, the perturbation function might only exist in a limited interval of the variable $x_{4}$ defined in Fig. 4. In addition to
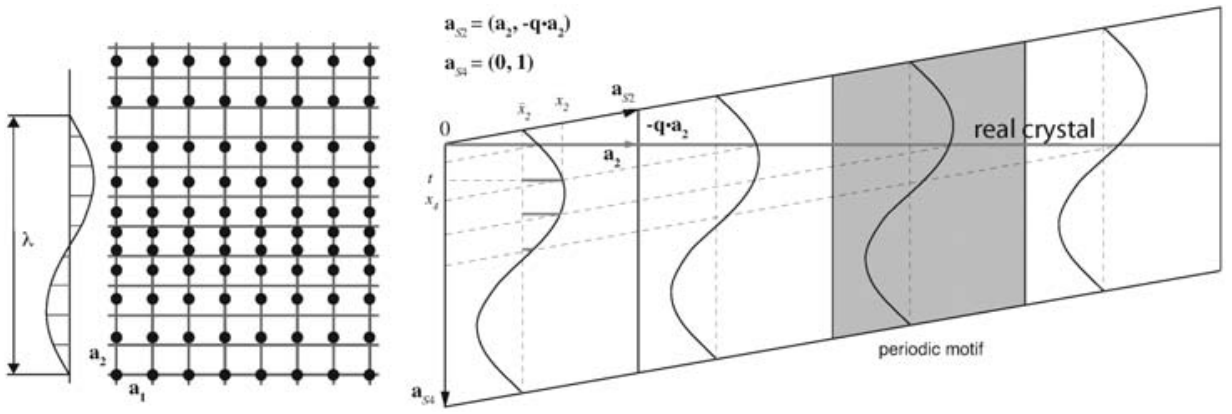

Fig. 4. Representation of a simple displacive modulation in superspace. (Left) A periodic array of points along $\mathbf{a}_{1}$ is subject to a transversal modulation along $\mathbf{a}_{2}$ with wavelength, $\lambda$, independent of $\mathbf{a}_{1}$ and $\mathbf{a}_{2}$. (Right) Representation of the displacive modulation in a section of superspace. 
'displacement' modulations, cases of 'density' modulations might also exist. Such an example is illustrated in Fig. 5 (right). This example illustrates the case of layer structures where alternating sequences of compact layers in the $\mathrm{A}, \mathrm{B}$ or $\mathrm{C}$ positions might occur. These are just a few examples and the interested reader might consult the textbooks by Janssen et al. (2007) and van Smaalen (2007) for others.

At the end of this section, it is appropriate to redefine the concept of crystals. A material is a crystal if it has essentially a sharp diffraction pattern. By recombining equations 1 and 2 and rewriting $\mathbf{H}$ in the form:

$$
\mathbf{H}=h_{1} \mathbf{a}_{1}^{*}+h_{2} \mathbf{a}_{2}^{*} h_{3} \mathbf{a}_{3}^{*}+\cdots+h_{n} \mathbf{a}_{n}^{*}
$$

where $n$ is the 'rank', i.e. the minimal number of integer indices required to fully characterize any diffraction pattern in a space of $d$ dimensions. If $n=d$, relation 5 describes a 'periodic' crystal. Otherwise, if $n>d$, the same relation describes an 'aperiodic' crystal. Note that the new definition of a crystal is done in reciprocal space and not in direct space as it used to be. Until now, any attempt to define a crystal in direct space failed. In other words, we need to explore the diffraction pattern of a crystal before we can assign it to one or the other category.

A crystal is 'incommensurately' modulated if at least one of the coefficients in equation 2 is irrational. Otherwise, the crystal is 'commensurately' modulated, which, in classical crystallography, is also called a superstructure.

\section{Symmetry in superspace}

The development of superspace could not have been successful without a complete development of a symmetry theory. Credit to P.M. de Wolff for having considered for the first time, in 1974, the description of a structure exhibiting satellite reflections in a space of higher dimension with the example of $\gamma-\mathrm{Na}_{2} \mathrm{CO}_{3}$. The theory of superspace symmetry is now well established and included in the International Tables for X-ray Crystallography, vol. C (Janssen et al., 1992). The theory is an extension of the classical space group symmetry which is used to describe conventional structures in three dimensions. A space group symmetry operation is a transformation of space

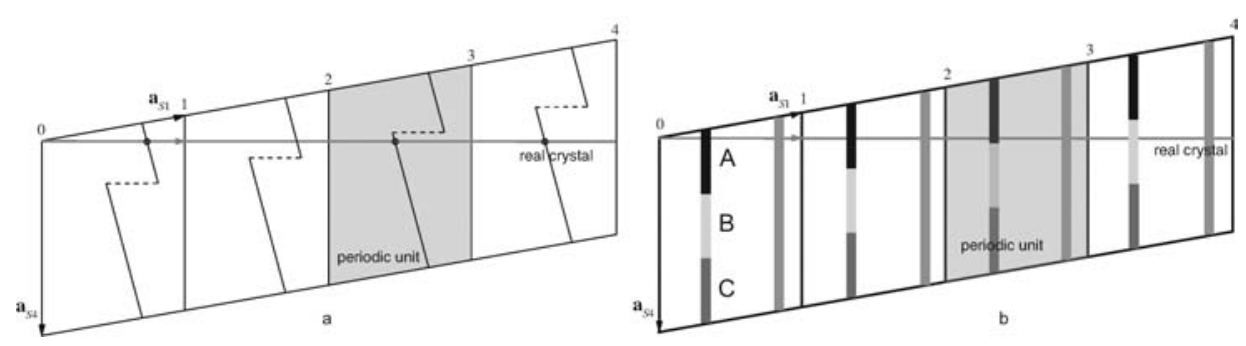

Fig. 5. Possible displacive and density modulation functions encountered in practical cases: (left) a sawtooth function; (right) a density modulation function representing different types of layers in the A, B or C positions. 
leaving the density function unchanged:

$$
\rho(\mathbf{r})=\rho(R \mathbf{r}+\mathbf{v})
$$

This transformation consists of a rotational part in form of the matrix $R$ acting on a point $\mathbf{r}$ followed by a translation $\mathbf{v}$. In superspace, the corresponding expression is very similar. Here the subscript $S$ refers to the superspace:

$$
\rho_{S}(\mathbf{r})=\rho\left(R_{S} \mathbf{r}_{S}+\mathbf{v}_{S}\right)
$$

The matrix $R_{S}$ defined in equation 7 is subject to some additional conditions, i.e. it should be $3+1$ reducible in $(3+1) \mathrm{D}$ superspace:

$$
R_{S}=\left(\begin{array}{cc}
R & 0 \\
R_{M} & R_{I}
\end{array}\right) \quad \text { where } R_{M}=\mathbf{q} R-R_{I} \mathbf{q}
$$

In general, the modulation vector $\mathbf{q}$ (equation 2 ) can be decomposed into a 'rational' and 'irrational' part, $\mathbf{q}=\mathbf{q}_{\mathrm{r}}+\mathbf{q}_{\mathrm{i}}$. For example, the rational part of $\mathbf{q}=\left(\alpha 0^{1 / 2}\right)$ is $1 / 2$. It can be shown that for all symmetry operation in superspace, the following condition holds

$$
\mathbf{q}_{i} R-R_{I} \mathbf{q}_{i}=0
$$

With the two-component formulation, the 'external' and 'internal' space dimensions are separated and we obtain the following relation by omitting the indices for the external variables:

$$
\rho_{S}\left(\mathbf{r}, \mathbf{r}_{I}\right)=\rho_{S}\left(R \mathbf{r}+\mathbf{v}, R_{I} \mathbf{r}_{I}+\mathbf{v}_{I}\right)
$$

In this expression, it is assumed that the selection of the pair of operators $R$ and $R_{I}$ uniquely defined the $R_{M}$ term. We can gain some further simplifications by limiting ourselves to superspace transformations in $(3+1) \mathrm{D}$. In this case, the internal dimension is 1 and $R_{I}=\varepsilon= \pm 1$. By definition

$$
\mathbf{r}_{I}=t=x_{4}-\mathbf{q} \cdot \mathbf{r}
$$

(as illustrated in Fig. 4) and it can be shown that $\mathbf{v}_{I}=\tau-\mathbf{q}_{i} \cdot \mathbf{v}$. By substituting relation 11 , the superspace transformation in $(3+1) \mathrm{D}$ becomes

$$
\rho_{S}(\mathbf{r}, t)=\rho_{S}\left(R \mathbf{r}+\mathbf{v}, \varepsilon t+\tau-\mathbf{q}_{I} \mathbf{v}\right)
$$

From this expression, we can conclude that any superspace transformation consists of two parts, the external part which is similar to one of the 230 space groups in $3 \mathrm{D}$ in addition to an internal part. In $(3+1) \mathrm{D}$, the value of $\varepsilon$ can be deduced easily from the transformation of modulation vector $\mathbf{q}$ and thus only $\tau$ needs to be specified. With this in mind, we can generalize the $3 \mathrm{D}$ space group symbols by adding the internal components in order to create the corresponding superspace symbol.

As an example, let us consider a (3+1)D superspace group taken from the reference of the International Tables for X-ray Crystallography, vol. C (Janssen et al., 1992). The

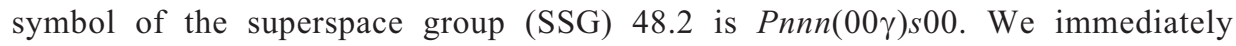
recognize the first (external) part of the 3D orthorhombic space group Pnnn. The second part between parentheses gives the components of the modulation vector $\mathbf{q}$ (equation 2 ). 
Obviously, this vector is parallel to the c axis. The last part characterizes the internal space components of the three symmetry operations listed after the letter $P$. The symbol $s$ indicates that the internal component $\tau$ of the first glide plane $n$ (normal to a) is $1 / 2$ resp. 0 for the second glide plane normal to $\mathbf{b}$. The third $n$ glide refers to the irrational part of the modulation vector. The value of $\tau$ depends on the selection of the origin of the internal space, which can be freely selected. Thus, the last digit of the symbol (0) indicates that the origin was selected on the inversion center at $\left(1 / 4^{1 / 4} / 4\right)$.

Similar to $3 \mathrm{D}$, where the glide components generate systematic absences in the diffraction patterns, this is also the case in superspace for both the external and internal translation components. The International Tables for X-ray Crystallography, vol. C (Janssen et al., 1992), lists the following systematic absences for this superspace group:

$$
\text { 0klm: } k+l+m=2 n \quad h 0 l m: h+l=2 n \quad h k 00: h+k=2 n
$$

In most cases, the systematic absences of modulated crystals reduce the number of possible superspace groups to a unique case or generally to a very small number of alternatives.

The number of four-dimensional space groups is 4894 whereas the number of $(3+1) \mathrm{D}$ superspace groups is 775 . Apparently $(3+1) \mathrm{D}$ are four-dimensional space groups with additional restrictions associated with the different properties of the external and internal space dimensions. For example, in 4D, one might consider permutations between the four space dimensions similar to the permutations of the three dimensions in the cubic space groups. This is not possible in superspace where the internal and external dimensions cannot be permuted, therefore the systematic use of the $(3+1) \mathrm{D}$ notation.

For simplicity, we have limited our considerations to $(3+1) \mathrm{D}$ superspace examples. Needless to say higher-dimensional superspace groups up to $(3+3) \mathrm{D}$ have not only been tabulated in the literature (e.g. Stokes et al., 2011) but they have also been applied to examples of crystalline structures. In the next section, we shall deal with the measurement and solution of modulated structures in superspace.

\section{Measurements and resolution of modulated structures from diffraction data}

Similar to treatment of symmetry in superspace, which is an extension of the symmetry in $3 \mathrm{D}$, the derivation of the electron density relation $\rho(\mathbf{r})$ in superspace is also based on an extension of the density in 3D. Independently of the rank (equation 5) of $\mathbf{H}$, the electron density satisfies the following relation:

$$
\rho(\mathbf{r})=1 / v \Sigma_{\mathbf{H}} F_{\mathbf{H}} \exp (-2 \pi \mathbf{i H} \cdot \mathbf{r})
$$

The only difference with the $3 \mathrm{D}$ expression is that $\mathbf{H}$ and $\mathbf{r}$ have $n$ components, where $n$ is the rank of $\mathbf{H}$.

The structure factor of a structure described in $(3+1) \mathrm{D}$ superspace is given by the following expression:

$$
F_{\mathbf{H}}=\Sigma_{\mu} f_{\mathbf{H}}^{\mu} \exp \left(-2 \pi \mathbf{i} \mathbf{H} \cdot \mathbf{r}^{\mu}\right) \times \int_{0}^{1} \mathrm{~d} t p^{\mu}(t) \exp \left[\exp \left(-2 \pi \mathbf{i} \mathbf{H} \cdot \mathbf{r}^{\mu}\right)\right]
$$


which essentially consists of two parts. The first part is very similar to the classical treatment of the structure factor with a summation over the $\mu$ atoms in the unit cell defined in superspace. The second part deals with the internal space dimension. The integration is performed over the internal variable, $t$, defined in equation $11 ; p^{\mu}$ is a population parameter, which might also express a density modulation function and the vector $\mathbf{u}^{\mu}$ gives the displacement of the $\mu$ atom from the average position along the internal coordinate $t$ as illustrated in Fig. 4. In practical cases, this integration is replaced by a numerical approximation and the shape of the displacement curve is obtained during the structure solution and refinement process.

The current generation of automatic diffractometers is, in most cases, able to collect a complete set of intensities with up to six indices. This has been greatly facilitated by the diffusion of area detectors like CCD or pixel detectors. The existence of satellite reflections can be detected easily a posteriori from the reconstruction of diffraction layers thus allowing the identification of the modulation vector(s) and consequently the indexing of the intensities once the full data collection is performed.

Once the intensities are collected and corrected for the usual factors, the next step in the structural analysis is to solve the structure. We shall describe two methods which allow us to obtain good model structures. The first method can be considered as a trial and error method and consists of two steps. The first is to solve the so-called average structure, which is obtained by ignoring the satellite reflections. The symmetry of this structure belongs to one of the classical 230 space groups and therefore the classical methods (Patterson, direct, etc.) can be applied to derive the first structural approximation. The second part assumes that the superspace group symmetry is known from the systematic absences and uses the least-squares refinement to complete the structure by finding the modulation functions of each single atom by trial and error. In order to find the optimal solution, various modulation functions can be applied until the most plausible model satisfying the structural and chemical characteristics is found. The final step of the structure solution is obtained following the full convergence of the optimization process.

One should also mention here that the Patterson and direct methods have also been applied in higher dimensions in the early days of developments. Currently, they are used infrequently and will not be further described in this context.

The second and perhaps more elegant method is based on the charge flipping (CF) algorithm proposed by Oszlányi and Sütó $(2004,2005)$. The great advantage of this method is that the structure can be solved directly in superspace without the intermediary step in 3D as in the previous method. The following scheme (equation 15) illustrates the CF algorithm which is an iterative process consisting of four steps. The algorithm starts from the square root of the intensity measurements on an arbitrary scale representing the moduli of the structure factors. Initially the phases of the structure factors are missing and consequently replaced by arbitrary or zero phases. The first step uses the inverse Fourier transform of the structure factors to obtain an arbitrary density function in superspace. Of course, this density should be either positive or zero everywhere. The second step (the inversion step) replaces every density point, which is smaller than a small positive value, $\delta$, by its inverse value in 
order to obtain the density $g_{\mathbf{r}}$. In the third step, this density is Fourier transformed in order to obtain a new set of structure factors, $G_{\mathbf{H}}$. The last step of the algorithm is to substitute the modulus of $G_{\mathbf{H}}$ by the experimental moduli. This process is repeated iteratively until the structure is solved.

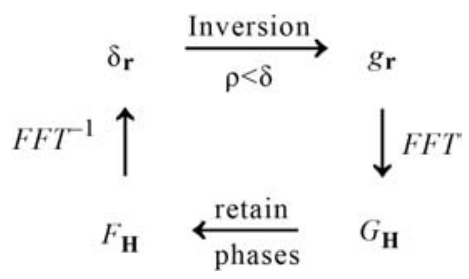

In most cases, the convergence is obtained after some hundred iterations or a small multiple of it. The only free parameter is the magnitude, $\delta$. This parameter is linked to the standard deviation of the measurements and can easily be obtained a priori.

Another advantage of this method is that the superspace group symmetry of the structure is not required. Therefore, it can be deduced a posteriori and checked by the final least-squares refinement of the structure.

Before closing this section, we shall describe the results of a structural refinement in superspace with the example of an oxygen-deficient synthetic compound with composition $\mathrm{LiZnNb}_{4} \mathrm{O}_{11.5}$ (Morozov et al., 2010). This structure is a superstructure of $\alpha-\mathrm{PbO}_{2}$. However, it is more convenient to treat it as a commensurately modulated structure with lattice parameters $a=4.72 \AA, b=5.73, c=5.03 \AA, \gamma=90.05^{\circ}$, modulation vector $\mathbf{q}=0.3 \mathbf{a}^{*}+1.1 \mathbf{b}^{*}$ and superspace group $P 112_{1} / n(\alpha \beta 0) 00$. The treatment in superspace has many advantages, one of which is to allow for a unified description and treatment of all members of the family of compounds $\mathrm{Li}_{2} \mathrm{O}-\mathrm{ZnO}-\mathrm{Nb}_{2} \mathrm{O}_{5}$, including commensurate $\left(\mathrm{LiNb}_{3} \mathrm{O}_{8}, \mathrm{ZnNb}_{2} \mathrm{O}_{6}, \mathrm{ZnTa}_{2} \mathrm{O}_{6}\right)$ and incommensurate (e.g., $\mathrm{ZnTa}_{2} \mathrm{O}_{6}$ ) members with the same superspace symmetry. Another important advantage concerns the solution and refinement of this complex structure, which is greatly facilitated in superspace and reduces the number of refined parameters.

The model of the resulting structure determination is illustrated in Fig. 6. The unit cell in the solid line corresponds to the $\alpha-\mathrm{PbO}_{2}$ cell whereas the dotted line represents the 10-fold supercell. Four different types of metal-oxygen octahedra can be distinguished each containing in its centre either a single atom (dark blue: $\mathrm{ZnO}_{6}$ or red: $\mathrm{NbO}_{6}$ ) or a combination of them (yellow: various combinations of $\mathrm{Li}$ and $\mathrm{Nb}$ or light blue: $1 / 3 \mathrm{Zn}$ and $2 / 3 \mathrm{Nb}$ ). The different types of octahedra form layers normal to the modulation vector $\mathbf{q}$ and the structure can be considered as a density modulation resulting from the distribution of cations, which tend to be ordered.

The structure was solved from powder diffraction data collected on a synchrotron beamline with the Jana 2006 software (Petŕíček et al., 2006). Figure 7 illustrates various sections of the electron density of the positional modulations of $\mathrm{Li}, \mathrm{Zn}$ and $\mathrm{Nb}$ along the internal coordinate $x_{4}$. The colour code of the positional modulation is identical to that used for metal octahedra represented in Fig. 6. The size of the domains of existence corresponding to each type of atoms was constrained to the chemical 
composition known beforehand during the refinement. The largest final residual electron density values were $0.17-0.23 \mathrm{e} / \AA^{3}$ thus illustrating the high quality of the refinement process in superspace even for powder diffraction data.

\section{A reinterpretation of the law of rational indices and occurrences of aperiodic structures}

Coming back to the work of GPP (1931), can we accept the conclusion that the law of rational indices is not of general validity? It would be disappointing that a law, which has been well accepted and confirmed many times over a period of 150 years, is only of limited value. The very elegant solution proposed by Janner and Dam (1989), which definitely solved the puzzle

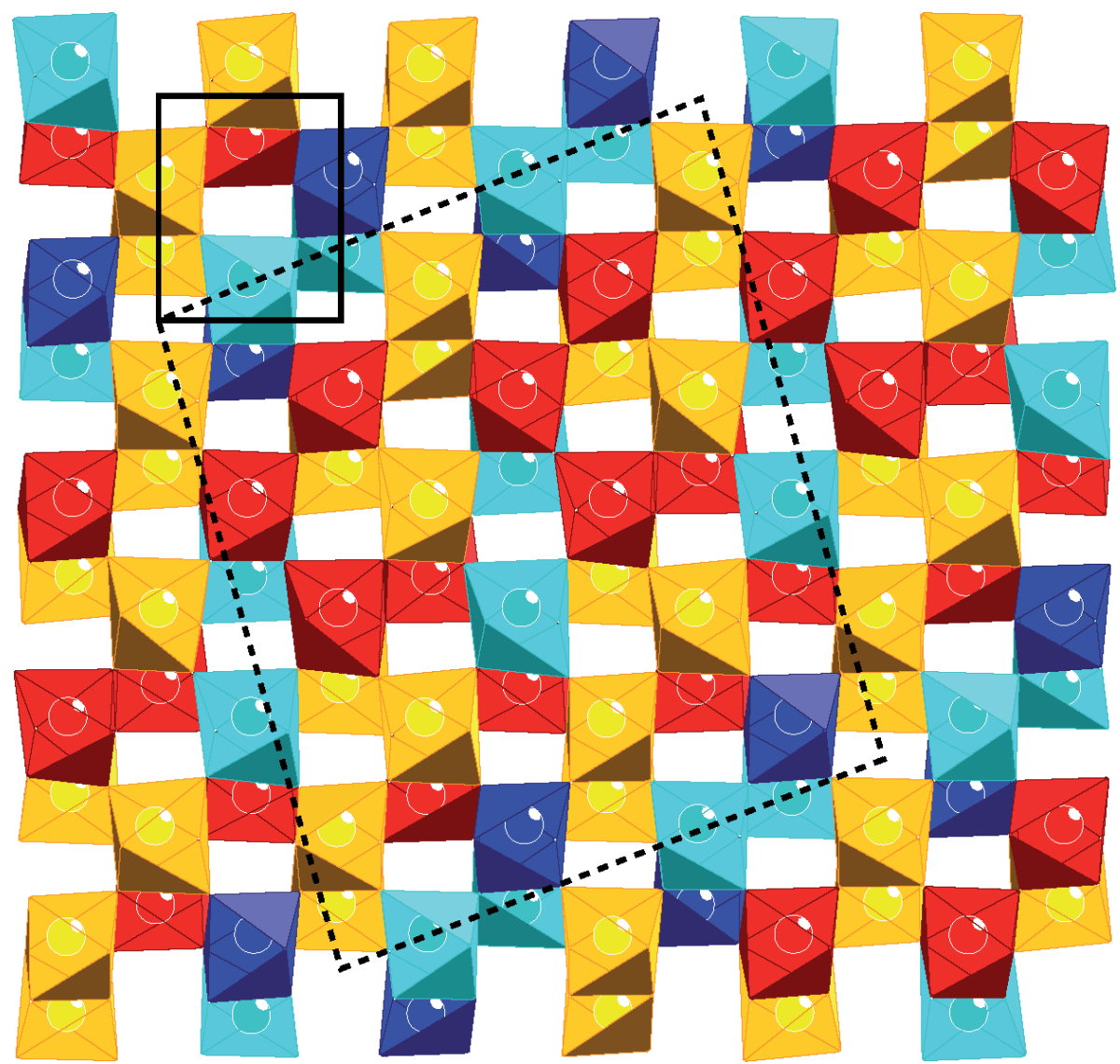

Fig. 6. Polyhedral view of $\mathrm{LiZnNb}_{4} \mathrm{O}_{11.5}$ (Morozov et al., 2010). Dark blue: $\mathrm{ZnO}_{6}$; red: $\mathrm{NbO}_{6}$; yellow: various concentrations of $\mathrm{LiO}_{6}$ and $\mathrm{NbO}_{6}$; light blue: $1 / 3 \mathrm{ZnO}_{6}$ and $2 / 3 \mathrm{NbO}_{6}$ polyhdra. The small cell (solid line) corresponds to the $\alpha-\mathrm{PbO}_{2}$ cell whereas the large cell (dashed line) illustrates the supercell. 

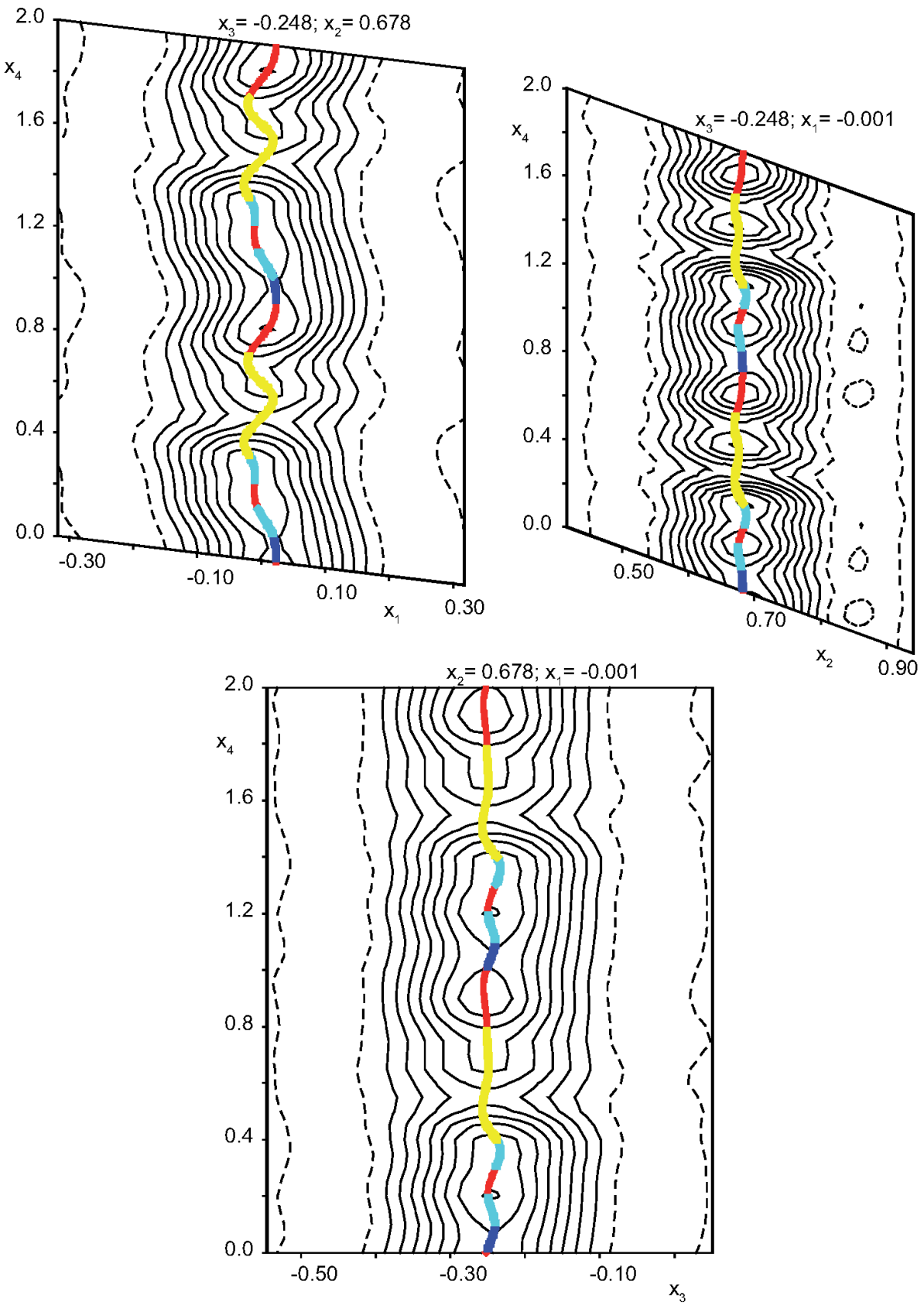

Fig. 7. Superspace representation of various electron density sections indicating the positional modulations of $\mathrm{Li}, \mathrm{Zn}$ and $\mathrm{Nb}$ in $\mathrm{LiZnNb} \mathrm{O}_{11.5}$. The central coloured lines correspond to the calculated atomic positions with the same colour code as in Fig. 6. 
of the calaverite mineral, shows that it is possible to accept the law of rational indices provided that we extend the number of indices characterizing each face (Fig. 2) of a crystal to its rank as defined in equation 5. This approach avoids not only the use of irrational indices but also the need to postulate the existence of a few interpenetrating structures belonging to different crystal classes in order to fully describe a crystalline sample. The example of calaverite is not an exception and many examples of crystal forms of modulated structures and quasicrystals have been found which require more than three indices to characterize their faces. For example, one of the phases of the metal-organic structure of $\left[\left(\mathrm{CH}_{4}\right)_{3} \mathrm{~N}\right]_{2} \mathrm{ZnCl}_{4}$ (Dam and Janner, 1986) which is incommensurately modulated exhibits faces which can only be indexed with four indices. We shall describe below the occurrence of the first naturally occurring quasicrystal, the mineral icosahedrite (Bindi et al., 2011), the faces of which can only be indexed with six indices. The interested reader can find more examples in the textbook of Janssen et al. (2007).

Note that the latest developments in diffraction methods with synchrotron and highly sensitive area detectors do not favour the discovery of new aperiodic crystalline forms. Firstly, the size of the samples, which tend to reach micron scales, and the use of automatic procedures to measure samples tend to ignore the morphological aspects of crystalline forms. On the other hand, the generalization of area detectors has been an important factor for the discovery of new aperiodic structures based on single-crystal diffraction patterns. The observation and identification of satellite reflections is greatly facilitated by its use instead of point detectors and it is probably due to their diffusion that the field of aperiodic structures has recently gained some importance. The identification of aperiodic structures by powder diffraction is more difficult. The detection of weak satellite reflections is often overseen and consequently the resulting structure refinement yields models which are often and wrongly interpreted as 'disordered'. As an example, a recent study on a series of scheelite-like structures (Arakcheeva and Chapuis, 2008) has revealed that some powder diagrams published in the ICDD database were indeed incommensurately modulated structures and the modulation vectors could be derived directly from the inclusion of a few neglected peaks and a reinterpretation of the powder diagrams. These examples are by no means unique and a more careful analysis of diffraction patterns of structures with complex stoichiometry would certainly reveal many more cases.

Aperiodic structures exist in all types of crystalline materials, from organic to inorganic compounds, in minerals, in metals and alloys and even in macromolecules. They also appear in compounds subject to temperature and pressure changes. In the next sections, we shall present some specific studies of aperiodic structures occurring in nature.

\section{Naturally occurring aperiodic structures}

In nature, minerals with strong and sharp satellites related to an aperiodic structure which can be used for a structural refinement with superspace formalism are rarely found. Nevertheless, there are several minerals with incommensurate satellites visible with electron diffraction. Indeed, incommensurately modulated structures can be found by 
TEM techniques in several rock-forming minerals including: clinopyroxenes (kosmochlor-diopside join; Sakamoto et al., 2003), quartz (e.g. Heaney and Veblen, 1991), feldspars (e.g. Yamamoto et al., 1984; Steurer and Jagodzinski, 1988; Kalning et al., 1997; Sanchez-Munoz et al., 1998), melilite (Bindi et al., 2001a and references therein), fresnoite (Bindi et al., 2006d), cancrinite-sodalite join (e.g. Hassan and Buseck, 1989, 1992; Xu and Veblen, 1995; Hassan, 2000; Hassan et al., 2004; Bolotina, 2006; Bolotina et al., 2006), nepheline (Withers et al., 1998; Angel et al., 2008; Friese et al., 2011), lazurite (Rastsvetaeva et al., 2002; Bolotina et al., 2003a,b, 2004), trydimite (e.g. Pryde and Dove, 1998), and mullite (Angel et al., 1991). Incommensurate modulations can also be found among sulfides, tellurides, and sulfosalts including bornite (Buseck and Cowley, 1983), pyrrhotite (Li and Franzen, 1996), calaverite (e.g. Caracas and Gonze, 2001), sylvanite (Krutzen and Inglesfield, 1990), rickardite (Schutte and de Boer, 1993), muthmannite (Bindi, 2008), proustite (Subramanian et al., 2000), cylindrite-franckeite series (Evain et al., 2006c; Makovicky et al., 2008, 2011) and sartorite (Pring et al., 1993). However, only a few incommensurate structures of minerals have been refined by means of the multidimensional approach namely: labradorite (Yamamoto et al., 1984), andesine (Steurer and Jagodzinski, 1988), melilite (Bindi et al., 2001a), lazurite (Bolotina et al., 2004 and references therein), fresnoite (Bindi et al., 2006d), levyclaudite (Evain et al., 2006c), calaverite (Bindi et al., 2009a), natrite (Arakcheeva et al., 2010), franckeite (Makovicky et al., 2011), nepheline (Friese et al., 2011) and wagnerite-group minerals (Lazic et al., 2014).

In the next part of this chapter, attention is focused on the description of outstanding examples of well characterized aperiodic mineral crystal structures. Among the incommensurately modulated structures we describe in detail the $(3+1) \mathrm{D}$-modulated structure of calaverite and natrite and the $(3+2) \mathrm{D}$-modulated structure of melilite and fresnoite; for the composite or intergrowth crystal structures, we analyse the minerals belonging to the pearceite-polybasite group and those of the cylindrite group, and, finally, for quasicrystals, we report briefly the story of the discovery of icosahedrite, the first naturally occurring quasicrystal.

\section{Naturally occurring incommensurately modulated structures}

\section{1. $(3+1) D$ incommensurately modulated structure: the cases of calaverite and natrite}

Calaverite, $\mathrm{AuTe}_{2}$, and natrite, $\mathrm{Na}_{2} \mathrm{CO}_{3}$, are probably the two most important minerals in the history of aperiodic structures. Calaverite, first identified by Ghent (1861), has already been mentioned in the introduction because of the difficulties mineralogists encountered in indexing crystalline specimens from different locations. It was later found that the diffraction pattern of calaverite exhibited satellite reflections, which pointed to the presence of an incommensurately modulated structure (Chapuis, 2003, and references therein).

On the basis of a transmission electron microscopy study, Van Tendeloo et al. (1983) discovered that the satellite reflections in calaverite were due to an incommensurately 
displacive modulation superimposed on the average $C 2 / m$ structure. Using the information gained from the TEM study, Dam et al. (1985) were able to clarify the morphology of calaverite by indexing the crystal faces with four indices, the extra index applying to $\mathbf{q}=-0.4095 \mathbf{a}^{*}+0.4492 \mathbf{c}^{*}$. Finally, Schutte and de Boer (1988) solved the incommensurately modulated structure of calaverite in the superspace group $C 2 / m(\alpha 0 \gamma) 0 s$. These authors showed that the modulation consists mainly of displacements of Te atoms and the observed modulations were interpreted in terms of valence fluctuations between $\mathrm{Au}^{+}$and $\mathrm{Au}^{3+}$. Later, Balzuweit et al. (1993) studied the variation of the modulation wave vector in synthetic calaverite as a function of temperature and silver content (up to 3.0 at.\% of $\mathrm{Ag}$ ) using X-ray diffraction and morphological techniques. More recently, Bindi et al. (2009a) studied various natural calaverite samples from different locations with chemical compositions $\mathrm{Au}_{1-x} \mathrm{Ag}_{x} \mathrm{Te}_{2}$, with $0 \leqslant x \leqslant 0.33$, extending the study of Schutte and de Boer (1988), and shedding new light on the origin of the structural modulations observed in this family of compounds. By means of higher dimensional structure refinements, Bindi et al. (2009a) showed that Ag atoms present two types of distribution on the Au sites, either randomly distributed or ordered. The original study of Schutte and de Boer (1988) was concerned with an ordered distribution of $\mathrm{Ag}$, which induces very strong valence fluctuations of $\mathrm{Au}$ in the structure. Bindi et al. (2009a) demonstrated another aspect of the $\mathrm{Au}_{1-x} \mathrm{Ag}_{x} \mathrm{Te}_{2}$ compounds, specifically those with random distributions of Ag on the Au position. By combining the results of both studies, these authors contended that the valence fluctuation of $\mathrm{Au}$ produces the structure modulation in $\mathrm{AuTe}_{2}$ (Fig. 8). Moreover, the ordered distribution of silver found by Bindi et al. (2009a) reinforces the valence fluctuation of Au. Conversely, a random distribution of Ag suppresses the valence fluctuation of $\mathrm{Au}$ and, therefore, their structural modulations. Apparently, natural samples can be found with the same composition but with both types of Ag ordering, which is not surprising considering the various growth conditions of the minerals.

Another interesting aspect of the $\mathrm{Au}_{1-x} \mathrm{Ag}_{x} \mathrm{Te}_{2}$ series pointed out by Bindi et al. (2009a) is related to the $(3+1) D$ superspace embedding of the calaverite structure type. These authors have shown that the same superspace model, independently of their 3D structures and periodicities, can describe all the samples with the same general formula. This formalism opens new perspectives, not only for a uniform description of this family of minerals, but also for other synthetic compounds related to the calaverite structure.

We mentioned earlier that the structure determination of $\mathrm{Na}_{2} \mathrm{CO}_{3}$ (Brouns et al., 1964; van Aalst et al., 1976) was essential in the development of the superspace approach. The structure of synthetic $\gamma-\mathrm{Na}_{2} \mathrm{CO}_{3}$ was later refined with greater accuracy using single-crystal XRD data (Dušek et al., 2003).

The first observation of satellite reflections pointing to an incommensurately modulated structure in natural natrite was by Zubkova et al. (2002) during a singlecrystal investigation of a crystal from Khibiny, Russia. However, the satellites were not measured and the authors refined only the average structure of this mineral sample. More recently, the incommensurate modulated structure of natural natrite, originating 


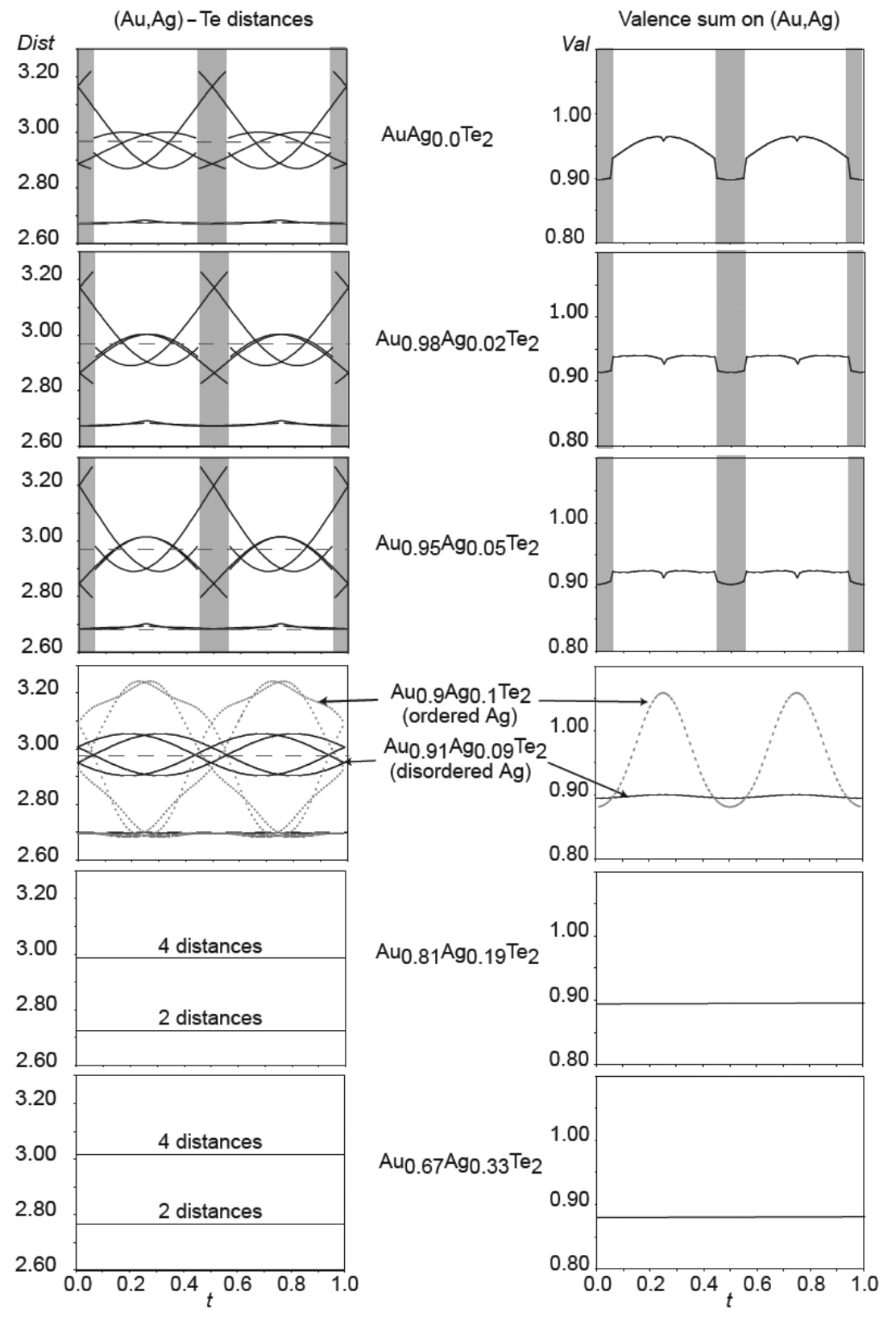

Fig. 8. Variation of the (Au,Ag)-Te distances (left column) and the bond valence sums on (Au,Ag) (right column) as functions of $t$ in Ag-bearing calaverites (Bindi et al., 2009a). Solid lines correspond to data from Bindi et al. (2009a); dashed graphs have been reconstructed using data published by Schutte and de Boer (1988). The grey fields indicate regions with $\mathrm{CN}=2+2$. Figure reproduced from Bindi et al. (2009a) with the permission of the Mineralogical Society of America. 
from the Lovozero alkaline massif (Mt. Karnasurt) and the Khibiny alkaline massif (Mt. Koashva), was studied in detail by Arakcheeva et al. (2010) using the superspace approach. The average structure of natrite can be mainly described as graphite-like layers formed by $\mathrm{Na} 3$ and $\mathrm{CO}_{3}$ ions, stacked along the $\mathbf{c}$ axis (Fig. 9). Additional Na1,2 octahedral-ions are located in the pseudo-hexagonal channels (van Aalst et al., 1976; Zubkova et al., 2002; Dušek et al., 2003). The face-sharing Na1,2 octahedra form columns which are connected by $\mathrm{CO}_{3}$ triangles along [010] and [100]. The modulation vector can be written as $\mathbf{q}=0.182(1) \mathbf{a}^{*}+0.322(1) \mathbf{c}^{*}$ and the superspace group is $C 2 / m(\alpha 0 \gamma) 0$ s (Arakcheeva et al., 2010).

The modulation in natrite is mainly associated with the $\mathrm{Na}$ crystal-chemical environment and with its role in participating in the second coordination sphere of the carbon atoms. As can be deduced from Fig. 10, the coordination number $(\mathrm{CN})$ of Na1,2 can be better described as $4+2$, where 4 distances are shorter than $2.3 \AA$, and 2 distances are $\sim 2.4 \AA$. The Na3 site has been reported as a $7+2$-fold coordinated with $7 \mathrm{Na}-\mathrm{O}$ distances in the range 2.584(1) - 2.669(1) $\AA$ and two elongated $\mathrm{Na}-\mathrm{O}$ distances at 2.942(1) $\AA$ (Zubkova et al., 2002). It is evident from the modulation of the $\mathrm{Na} 3-\mathrm{O}$ distances (Fig. 10) that eight oxygen atoms are always close to $\mathrm{Na} 3$ (in the range $2.35-2.9 \AA$ ) without any preference for $\mathrm{CN}=7$. Therefore, the coordination number of $\mathrm{Na} 3$ is equal to 8 .

One final interesting remark concerns the $\mathrm{CO}_{3}$ group and its usual planarity in the crystal structures. This group seemed to be a completely rigid unit in the average structure of natrite refined by Zubkova et al. (2002). Arakcheeva et al. (2010), however, showed that the $\mathrm{C}-\mathrm{O}$ distances and the $\mathrm{C}-\mathrm{O} 2-\mathrm{O} 1-\mathrm{O} 1$ torsion angle (describing the deviation from planarity of the $\mathrm{CO}_{3}$ entity) are slightly modulated along $t$, the additional coordinate in superspace. The reasons for such a modulation were described in detail by Arakcheeva and Chapuis (2005) for synthetic $\mathrm{Na}_{2} \mathrm{CO}_{3}$. A small deviation

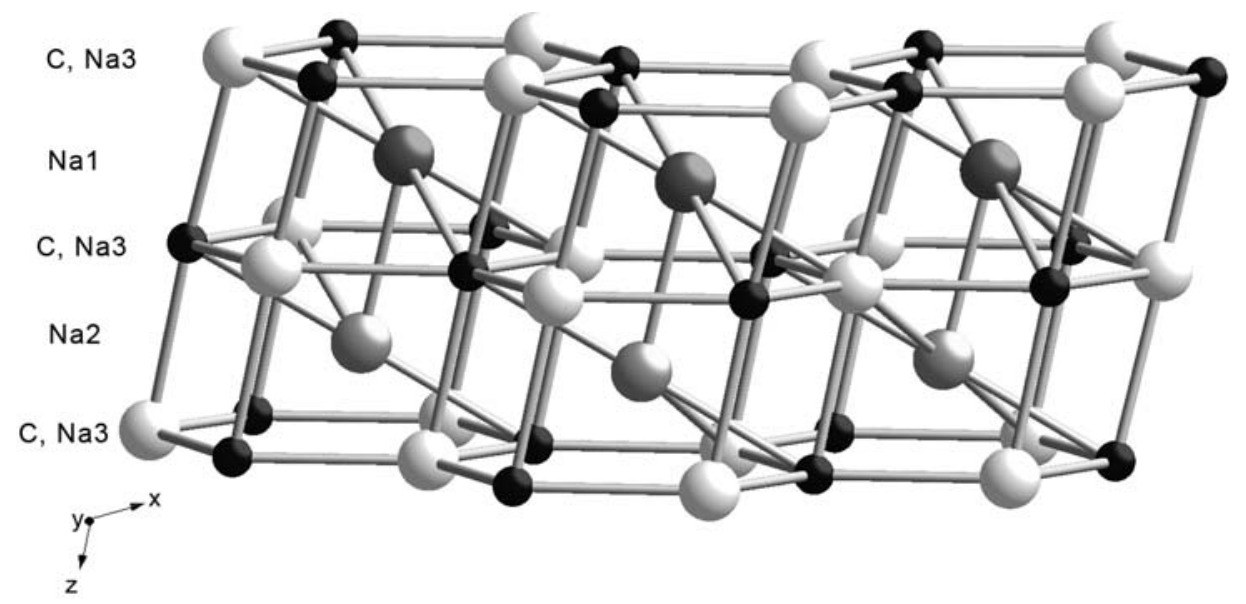

Fig. 9. Structure of the hexagonal modification of natrite, $\mathrm{Na}_{2} \mathrm{CO}_{3}$. The orientation of the structure is outlined. 


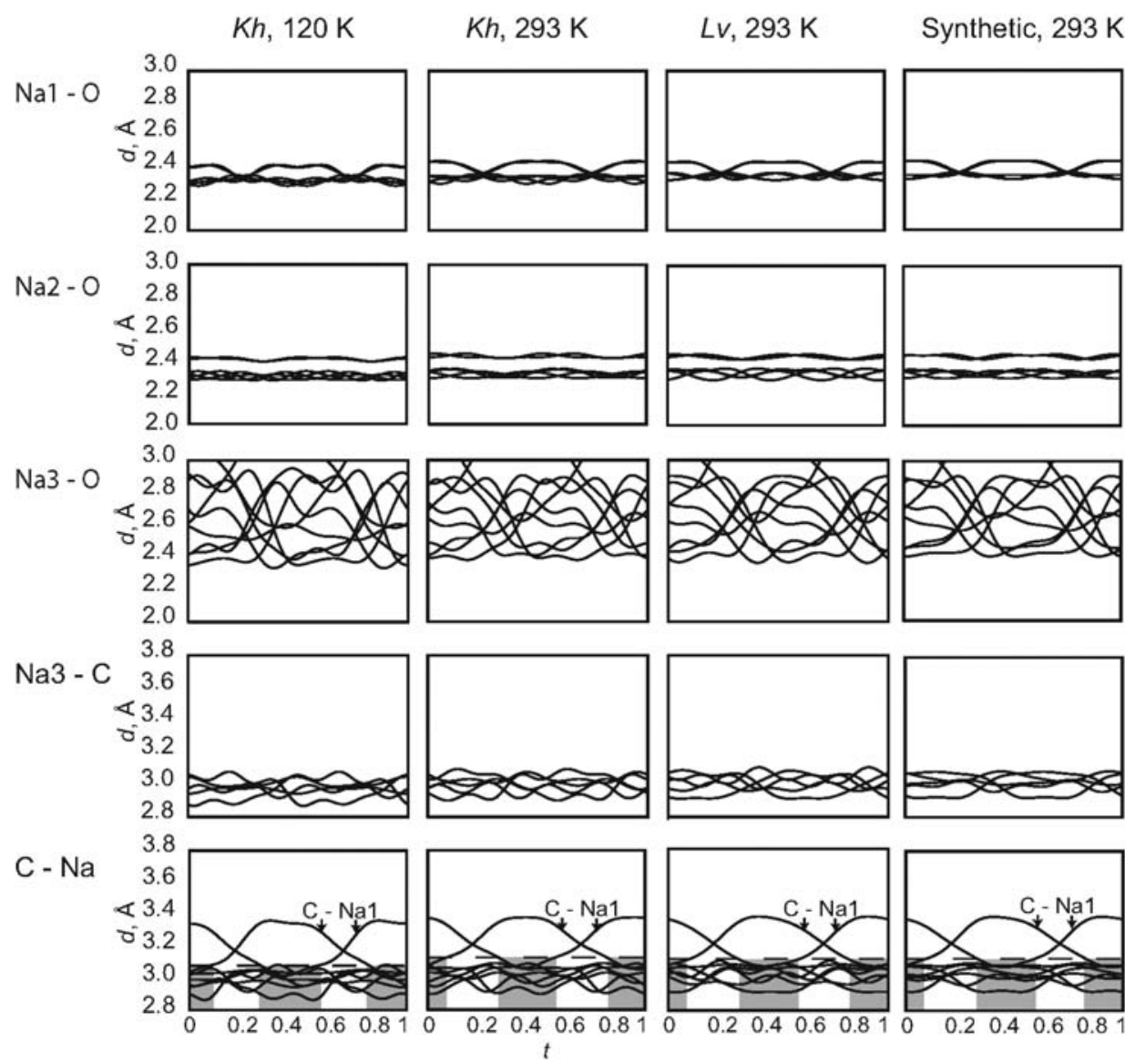

Fig. 10. Modulations of the interatomic distances along the $t$ axis in the structure of natrite from Khibiny (at both RT and $120 \mathrm{~K}$ ) and Lovozero, compared with the behaviour observed for synthetic $\mathrm{Na}_{2} \mathrm{CO}_{3}$ (Arakcheeva and Chapuis, 2005 - last column). In the C-Na vs. $t$ plots, the grey areas mark the regions with $7 \mathrm{Na}$ atoms in the $3.1 \AA$ vicinity of each C (reproduced from Arakcheeva et al. (2010) with the permission of the Mineralogical Society of America).

$\left(1-2^{\circ}\right)$ of the $\mathrm{C}-\mathrm{O} 2-\mathrm{O} 1-\mathrm{O} 1$ torsion angle from $0^{\circ}$ should also be mentioned, thus indicating positional displacements of $\mathrm{O}$ atoms, resulting in the small distortions of the $\mathrm{CO}_{3}$ group.

\section{2. $(3+2) \mathrm{D}$ incommensurately modulated structure: the cases of melilite and fresnoite}

Minerals of the melilite group exhibit a general chemical formula $\mathrm{X}_{2} T 1\left[(T 2)_{2} \mathrm{O}_{7}\right]$, where the cations $X$ occupy square antiprisms and consist mainly of Ca with minor amounts of $\mathrm{Na}$ and other elements (i.e. mainly $\mathrm{Ba}$ and $\mathrm{Sr}$ ). $T 1$ and $T 2$ tetrahedra differ from each other by their size: the larger $T 1$ generally hosts $\mathrm{Mg}$ and other medium-size 
tetrahedral cations such as $\mathrm{Fe}^{2+}, \mathrm{Mn}^{2+}, \mathrm{Fe}^{3+}$, and $\mathrm{Al}$; the smaller $T 2$ tetrahedron is generally occupied by $\mathrm{Si}$ to form the $(T 2)_{2} \mathrm{O}_{7}$ groups that typically occur in sorosilicates. The structure with space group $P \overline{4} 2{ }_{1} m$ consists of a two-dimensional linkage of corner sharing $T 1$ and $T 2$ tetrahedra, forming irregular pentagonal rings (Fig. 11). Some synthetic melilite-type compounds with $X$ occupied by calcium and $T 2$ by silicon, with $T 1=\mathrm{Mg}, \mathrm{Zn}, \mathrm{Co}$, or $\mathrm{Fe}^{2+}$, exhibit an incommensurately modulated phase at room temperature (Hemingway et al., 1986; Seifert et al., 1987; Armbruster et al., 1990; Hagiya et al., 1993).

The incommensurate modulation in melilite is two-dimensional, with two modulation vectors: $\mathbf{q}_{1}=\alpha\left(-\mathbf{a}_{1}^{*}+\mathbf{a}_{2}^{*}\right)$ and $\mathbf{q}_{2}=\alpha\left(\mathbf{a}_{1}^{*}+\mathbf{a}_{2}^{*}\right)$, where $\mathbf{a}_{1}^{*}$ and $\mathbf{a}_{2}^{*}$ are the tetragonal reciprocal axes of the basic unit cell and $\alpha=0.2815$ (3). As a consequence, all the reflections can be indexed by five integers, $h \mathrm{klmn}$, corresponding to the five-dimensional basis (equation 5) $\mathbf{H}=$ $h \mathbf{a}^{*}+k \mathbf{b}^{*}+l \mathbf{c}^{*}+m \mathbf{q}_{1}+n \mathbf{q}_{2}$, where $\mathbf{a}^{*}, \mathbf{b}^{*}$ and $\mathbf{c}^{*}$ are the reciprocal axes of the basic structure. The direction of the modulation vectors is along 110 and 110 and the coefficient $\alpha$ is approximately $2 / 7$ of the corresponding $d$ value (Fig. 12).

A similar incommensurate modulation was reported for fresnoite-type compounds (Markgraf and Bhalla, 1989; Markgraf et al., 1990; Höche et al., 1999). The mineral fresnoite, $\mathrm{Ba}_{2} \mathrm{TiSi}_{2} \mathrm{O}_{8}$, is structurally related to the melilite-group minerals. The parent structure, space group $\mathrm{P} 4 \mathrm{bm}$, consists of a two-dimensional array of corner-sharing $\mathrm{TiO}_{5}$ pyramids and $\mathrm{Si}_{2} \mathrm{O}_{7}$ groups. In the stacking of successive layers along [001], the ten-fold coordinated $\mathrm{Ba}$ cations are located about halfway between adjacent sheets (Fig. 13). Withers et al. (2002) investigated the incommensurate structure of a synthetic fresnoite by means of electron microscopy and pointed out that the primary modulation wave-vector has a $1 / 2 \mathbf{c}^{*}$ commensurate component in addition to an incommensurate component which runs along the basis diagonal of the parent structure with modulation vectors $\mathbf{q}_{1}=\alpha\left(-\mathbf{a}_{1}^{*}+\mathbf{a}_{2} *\right)$ and $\mathbf{q}_{2}=\alpha\left(\mathbf{a}_{1}^{*}+\mathbf{a}_{2} *\right)$ with $\alpha=0.3023(3)$, very similar to the distribution of satellites observed for melilites (Fig. 12) except for the commensurate component at $1 / 2 \mathbf{c}^{*}$.

Prior to the studies by Bindi et al. (2001a,b, 2006d), the presence of additional satellite reflections due to the incommensurate structure had never been observed in natural melilites or fresnoite. By means of the superspace approach, these authors carried out $(3+2)$-dimensional refinements of the incommensurately modulated structure of both the minerals.

For natural melilite, Bindi et al. (2001a) showed that the most important structural variations as a function of the internal components $t$ and $s$ of the $(3+2)$ superspace are observed for the $\mathrm{X}$-polyhedra with some distances reaching values greater than $3 \AA$. Thus, some oxygen atoms are no longer coordinated locally by Ca. Due to this feature, six-, seven- and eight-fold coordinations of the $X$ cation occur in different parts of the structure. A similar characteristic was observed by Bindi et al. (2006d) for natural fresnoite. As a consequence of the $\mathrm{Ba}$ and $\mathrm{O}$ positional modulation, eight-, nine-, and ten-fold Ba-coordinations occur throughout the structure. Interestingly, the change of coordination around the $\mathrm{Ca}$ (in melilite) and $\mathrm{Ba}$ (in fresnoite) atoms induces a deformation of the pentagonal rings, as seen from a projection of the two structures along [001] (Figs 11 and 13). The deformed pentagonal rings correspond to $\mathrm{Ca}$ 

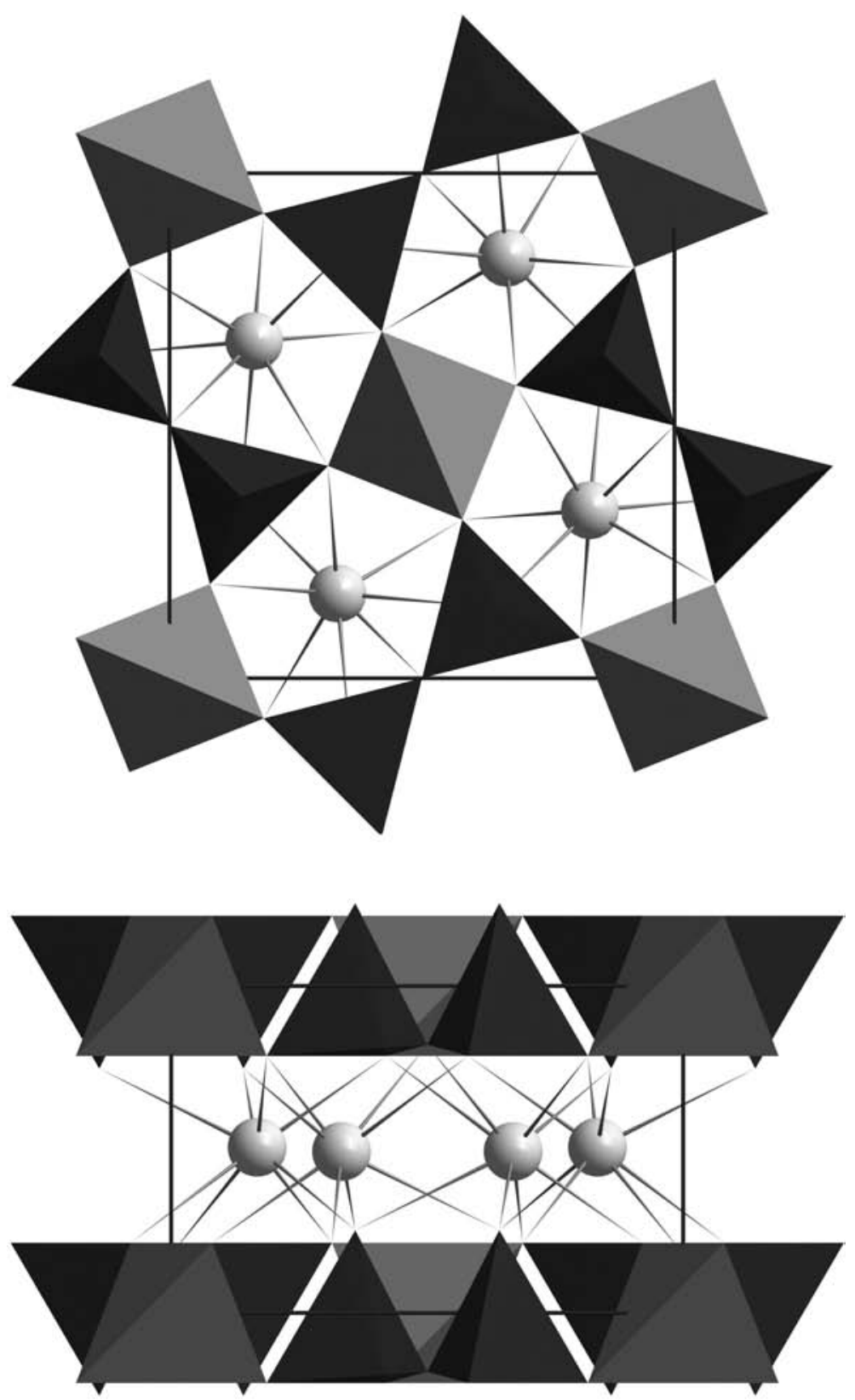

Fig. 11. The crystal structure of melilite projected down [001] (upper) and down [010] (lower). Light and dark grey tetrahedra refer to $T 1$ and $T 2$, respectively. White circles indicate the $X$ cations. 


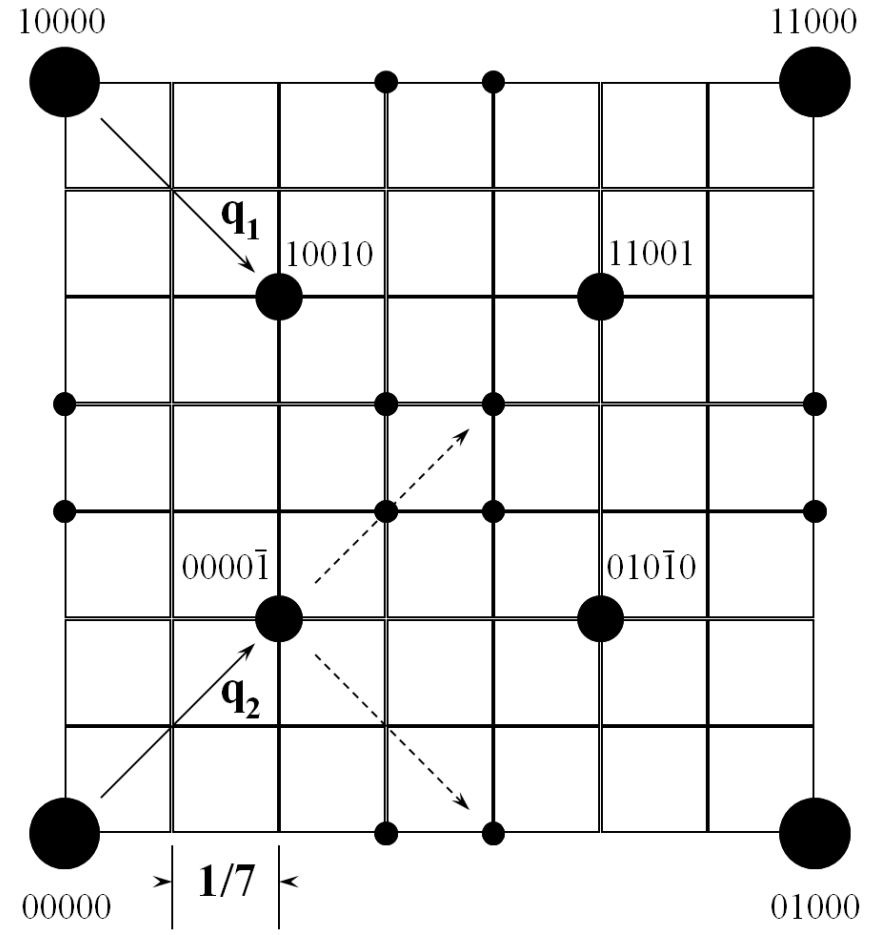

Fig. 12. Schematic view of the diffraction pattern in melilite. Main and satellite reflections (indexed on the basis of five indices) are represented with large and small black circles. The modulation $\mathbf{q}$ vectors are indicated.

(in melilite) and $\mathrm{Ba}$ (in fresnoite) atoms with increasing coordinations forming octagonal clusters (Fig. 14) closely resembling the configuration postulated by van Heurck et al. (1992), on the basis of transmission electron microscopy, for the synthetic $\mathrm{Ca}_{2} \mathrm{ZnGe}_{2} \mathrm{O}_{7}$ melilite-type compound.

\section{Naturally occurring composite modulated structures}

\subsection{The minerals of the pearceite-polybasite group}

The members of the pearceite-polybasite group of minerals exhibit the general formula $\left[(\mathrm{Ag}, \mathrm{Cu})_{6} \mathrm{M}_{2} \mathrm{~S}_{7}\right]\left[\mathrm{Ag}_{9} \mathrm{CuS}_{4}\right]$, with $M=\mathrm{As}$ (pearceite) or $\mathrm{Sb}$ (polybasite), and their structures have been characterized recently (Bindi et al., 2006a,b, 2006c; Evain et al., 2006a,b). On the whole, they can be described (Fig. 15) as a regular succession of two module layers stacked along the $c$ axis: a first module layer $A$ with composition $\left[(\mathrm{Ag}, \mathrm{Cu})_{6} M_{2} \mathrm{~S}_{7}\right]^{2-}$, and a module layer $B$ with composition $\left[\mathrm{Ag}_{9} \mathrm{CuS}_{4}\right]^{2+}$. In the structure, $M$ atoms form isolated $M \mathrm{~S}_{3}$ pyramids typically occurring in sulfosalts, copper links two sulfur atoms in a linear coordination, and silver occupies sites with coordination ranging from quasi-linear to almost tetrahedral (Bindi et al., 2006a). In 

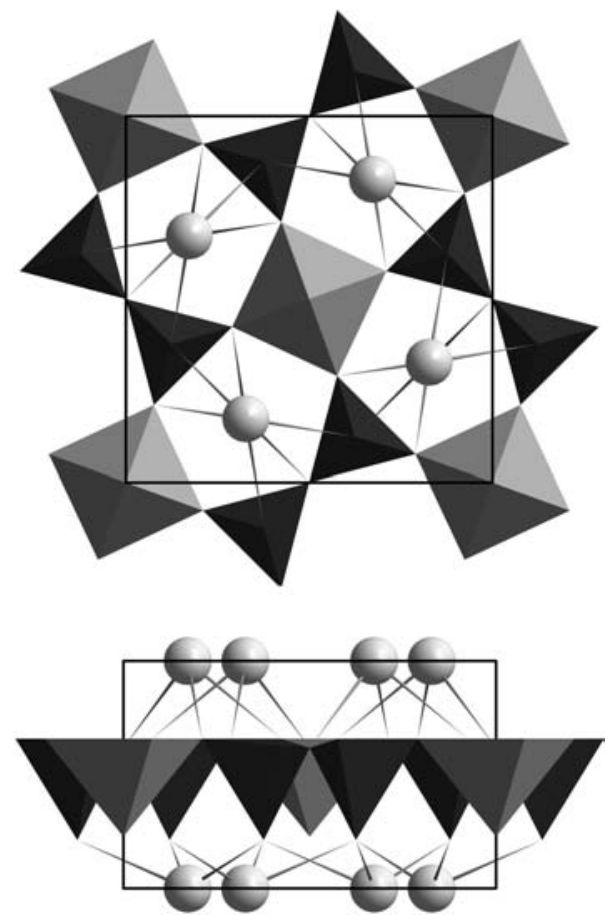

Fig. 13. The crystal structure of fresnoite projected down [001] (upper) and down [010] (lower). Interconnection of $\mathrm{TiO}_{5}$ pyramids (light grey) and $\mathrm{Si}_{2} \mathrm{O}_{7}$ groups (dark grey); white circles represent $\mathrm{Ba}$ atoms.

the $B$ layer the silver cations are found in various sites corresponding to the most pronounced probability density function locations of diffusion-like paths (Fig. 16, Bindi et al., 2006a).

The complex crystal-chemical features observed in these minerals were initially studied by Frondel (1963) who considered that this group of minerals could be divided into two series based on their unit-cell dimensions: (1) pearceite-antimonpearceite, characterized by a relatively high $\mathrm{Cu}$ content and a "small" unit cell $(a \approx 7.4-7.5, c \approx$ $11.9 \AA$ ) initially labelled ' 111 ' but more recently referred to using the more explicit polytype suffix 'Tac' (Bindi et al., 2007b), consistent with the notation of Guiner et al. (1984); and (2) polybasite-arsenpolybasite, characterized by a lower $\mathrm{Cu}$ content and doubled unit-cell parameters, initially labelled ' 222 ' but, more recently ' $M 2 a 2 b 2 c$ ' (Bindi et al., 2007b). Moreover, an additional unit cell of intermediate dimensions, initially labelled '221' or 'T2ac' (Bindi et al., 2007b), was discovered independently by Harris et al. (1965), Hall (1967), Edenharter et al. (1971) and Minčeva-Stefanova et al. (1979).

By means of LT and HT single-crystal X-ray diffraction, differential scanning calorimetry, and complex impedance spectroscopy, Bindi et al. (2006a) showed that all members of the pearceite-polybasite group present the same $P \overline{3} m 1$ high-temperature structure and are observed at room temperature either in their high-temperature (HT) fast-ion conductivity form or in one of the low-temperature (LT) fully ordered 

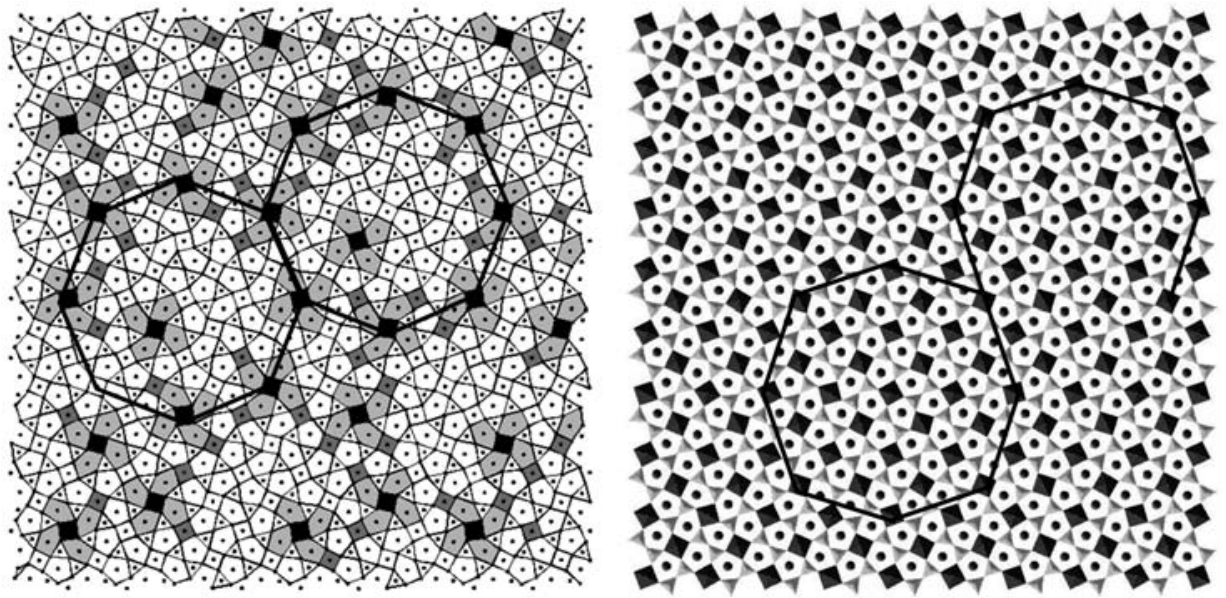

Fig. 14. Structural variations observed for the different polyhedra in melilite (left) and fresnoite (right) as a function of the fourth coordinate of the superspace $(t)$ with the fifth coordinate $(s)$ kept fixed at 0.00 . Triangles, squares and circles indicate Si-tetrahedra, Mg-tetrahedra (left) or Ti-pyramids (right) and Ca or Ba cations, respectively. The displacements for a given value of $t$ (or $s$ ) define a configuration that occurs somewhere in the real space. The configurations with close values of $t$ (or $s$ ) are not necessarily neighbouring in the real space. The deformed pentagonal rings hosting the large cations (Ca in melilite and $\mathrm{Ba}$ in fresnoite) form octagonal arrangements indicated with solid lines (see text for explanation).

(M2a2b2c unit-cell type), partially ordered (T2ac unit-cell type) or still disordered (Tac unit-cell type) forms, with transition temperatures slightly above or below room temperature. Below the transition temperature, the silver ions freeze in preferred structural sites. However, the ordering is not necessarily a long-range order. In cupropearceite and cupropolybasite (Bindi et al., 2007a), for example, the Tac unit-cell type and $P \overline{3} \mathrm{~m} 1$ space group are preserved down to $100 \mathrm{~K}$ (Bindi et al., 2006a). This peculiarity is to be related to the disorder which occurs at all temperatures within the $\left[(\mathrm{Cu}, \mathrm{Ag})_{6}(\mathrm{As}, \mathrm{Sb})_{2} \mathrm{~S}_{7}\right]^{2-} A$ module.

Recent TEM studies (Withers et al., 2008; Bindi et al., 2013) showed that these minerals exhibit a composite modulated structure, not visible either with conventional or with synchrotron X-ray diffraction. Such a composite modulated structure forms between two inherently incommensurate substructures: the first being an average primitive hexagonal, $\left[\mathrm{Ag}_{9}\right]^{9+}, 2 \mathrm{D} \mathrm{Ag}{ }^{+}$ion sub-structure (consisting of the $\mathrm{Ag}^{+}$ion diffusion paths within the $B$ modules - Fig. 16) and the second a $\left[(\mathrm{Ag}, \mathrm{Cu})_{6}(\mathrm{As}, \mathrm{Sb})_{2} \mathrm{~S}_{7}\right]^{2-}\left[\mathrm{CuS}_{4}\right]^{7-}$ framework sub-structure (formed by the $\left[\mathrm{S}(\mathrm{Cu}, \mathrm{Ag})_{6}\right]$ octahedra, the $(\mathrm{As}, \mathrm{Sb}) \mathrm{S}_{3}$ trigonal pyramids, and the [S-Cu-S] dumbbells, Fig. 17).

The composite modulation is evident with the appearance of relatively strong and well defined satellite reflections in addition to the main reflections forming a hexagonal reciprocal lattice (Fig. 18). At first glance, the observed satellites seems to suggest a $2 \mathrm{D}$ displacive modulation of the framework structure with incommensurate modulation wave vectors of the 


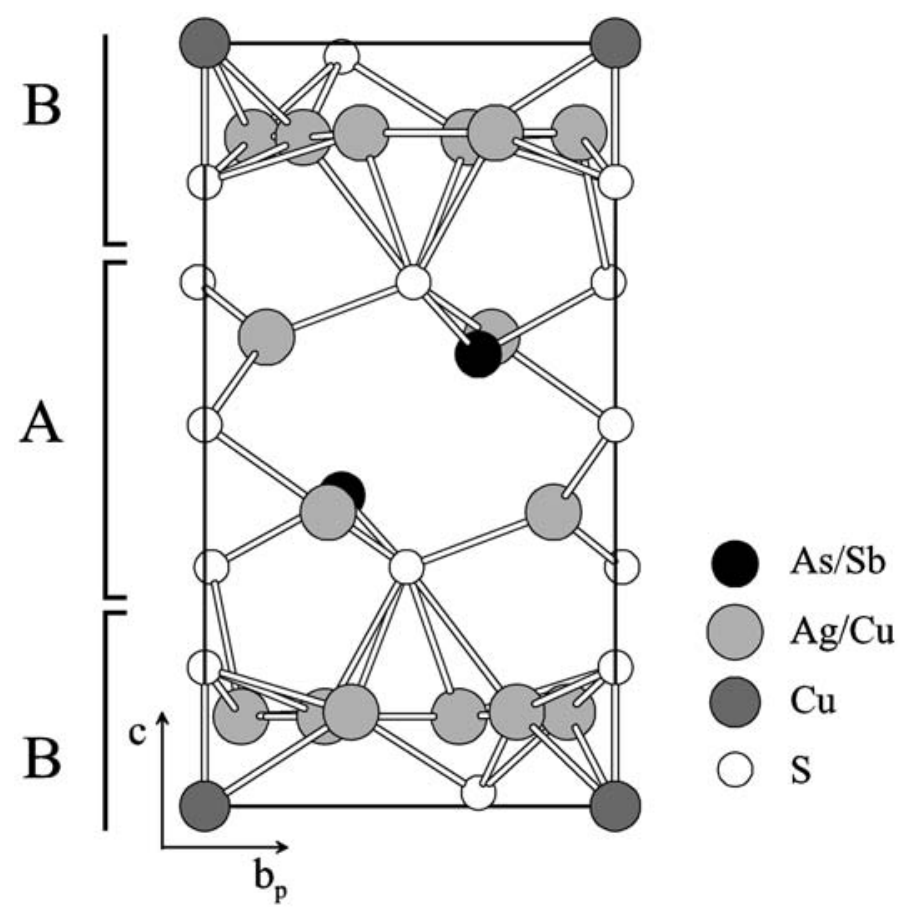

Fig. 15. Projection of the 111-structure (Tac polytype) of pearceite along the hexagonal $a$ axis, emphasizing the succession of the $\left[(\mathrm{Ag}, \mathrm{Cu})_{6} M_{2} \mathrm{~S}_{7}\right]^{2-} A$ and $\left[\mathrm{Ag}_{9} \mathrm{CuS}_{4}\right]^{2+} B$ module layers.

satellite reflections $\mathbf{q}_{1}=\alpha\left(\mathbf{a}_{\mathrm{F}}^{*}+\mathbf{b}_{\mathrm{F}}^{*}\right)$ and $\mathbf{q}_{2}=\alpha\left(\mathbf{a}_{\mathrm{F}}^{*}-\mathbf{b}_{\mathrm{F}}^{*}\right)$, where $\alpha \approx 0.39(1)$ and the subscript $\mathrm{F}$ indicates the framework structure. However, as outlined in detail by Withers et al. (2008) and Bindi et al. (2013), the apparent incommensurate modulation vectors can be interpreted more reasonably as "fundamental reciprocal lattice basis vectors of an average primitive hexagonal $\mathrm{Ag}$ ion substructure", with the basis vectors $\mathbf{a}_{\mathrm{Ag}}^{*}=\alpha\left(\mathbf{a}_{\mathrm{F}}^{*}-2 \mathbf{b}_{\mathrm{F}}^{*}\right)$ and $\mathbf{b}_{\mathrm{Ag}}^{*}=\alpha\left(2 \mathbf{a}_{\mathrm{F}}^{*}-\mathbf{b}_{\mathrm{F}}^{*}\right)$ with $\alpha \approx 1.39$. This interpretation is mainly due to the observed strong intensity asymmetry of the satellite reflections (see arrows in Fig. 19) surrounding individual parent Bragg reflections, with the satellites at the high-angle side showing much higher intensity than those of the low-angle side, which are scarcely discernible. Several authors (Carter and Withers, 2004; Norén et al., 2005) have provided conclusive proof of the incompatibility of this observation with a conventional incommensurate modulation and suggested, instead, a composite modulated structure.

Bindi et al. (2013) have studied by means of transmission electron microscopy the low- $(90 \mathrm{~K})$ and ultra-low- $(4.2 \mathrm{~K})$ temperature behaviour of the $\mathrm{Cu}$-rich members of the pearceite-polybasite group, i.e. cupropearceite and cupropolybasite. They found a similar behaviour to that observed for $\mathrm{Cu}$-poor pearceite and polybasite (Tac members) at room temperature (Withers et al., 2008), but a new structural feature appeared at ultra-low temperature (Fig. 20). Estimates of the relevant wave vectors $\mathbf{q}_{1}=\alpha\left(\mathbf{a}_{\mathrm{F}}^{*}+\mathbf{b}_{\mathrm{F}}^{*}\right)$ and $\mathbf{q}_{2}=\alpha\left(\mathbf{a}_{\mathrm{F}}^{*}-\mathbf{b}_{\mathrm{F}}^{*}\right)$ of the incommensurate modulation, indeed, gave approximate $\alpha$ 


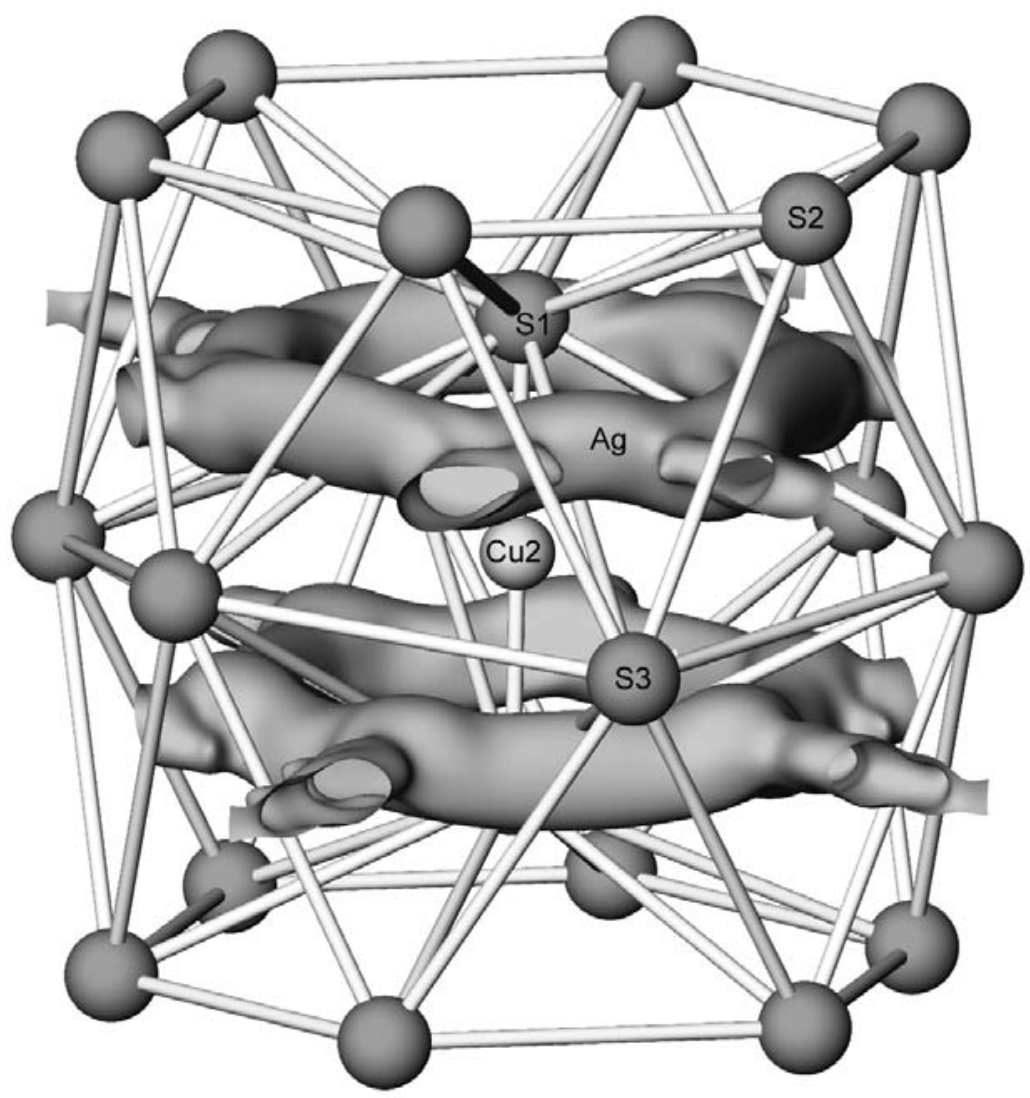

Fig. 16. Non-harmonic joint probability density isosurface for silver in the pearceite structure at RT in the $\left[\mathrm{Ag}_{9} \mathrm{CuS}_{4}\right]^{2+}$ layer extended with $\mathrm{S} 2$ atoms, exhibiting the silver diffusion in the ab plane (Bindi et al., 2006a). Level of the map: $0.05 \AA^{-3}$. Sulfur and copper atoms at an arbitrary size.

values of 0.39 at room temperature, 0.40 at $T=90 \mathrm{~K}$, and 0.50 at $T=4.2 \mathrm{~K}$. The remarkable displacement noticed in the positions of the satellite reflections with decreasing temperature means that the modulation at $4.2 \mathrm{~K}$ approaches the wave vector $\alpha=0.50$, which would correspond to a commensurate superstructure. Such behaviour is known from other compounds as, for example, certain melilite-type compounds where a transformation from the incommensurate high-temperature phase into a lowtemperature commensurate lock-in phase has been observed (Riester et al., 2000; Hagiya et al., 2001; Schaper et al., 2001; Bagautdinov et al., 2002; Jia et al., 2006).

\subsection{The cylindrite-type minerals}

Cylindrite-type minerals, which take their name from the typical cylindrical morphology of the crystals, are known as 'two-dimensional misfit' structures 


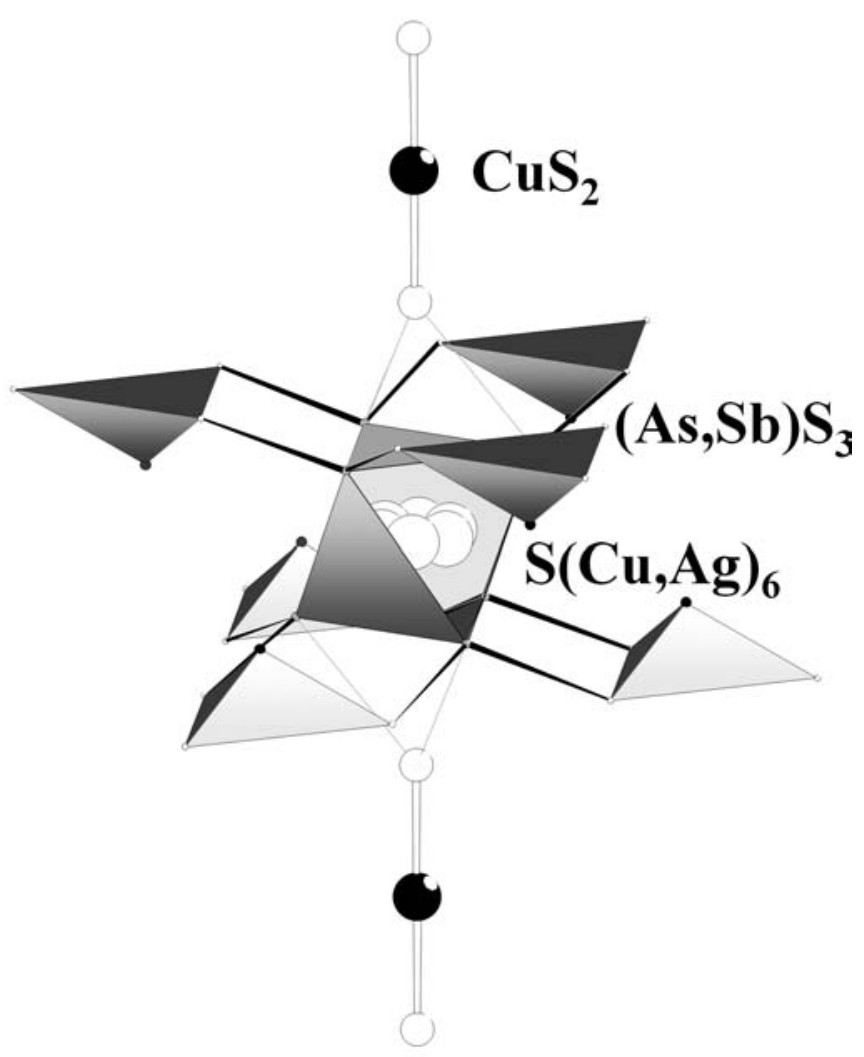

Fig. 17. A portion of the overall structure highlighting the connectivity of the fundamental building blocks $\left[\right.$ i.e. $\mathrm{CuS}_{2},(\mathrm{As}, \mathrm{Sb}) \mathrm{S}_{3}$ and $\left.\mathrm{S}(\mathrm{Ag}, \mathrm{Cu})_{6}\right]$ of the framework substructure in the average $P \overline{3} m 1$ crystal structure (Tac polytype) of pearceite and polybasite (reproduced from Withers et al. (2008) with the permission of Elsevier).

(Makovicky and Hyde, 1981, 1992; Evain et al., 2006c; Makovicky et al., 2008, 2011). According to Wiegers and Meerschaut (1992), this kind of modulated compound exhibits complex layered crystal structures of the composite type, in which there is the regular alternation of two types of layers, having one or two of their in-plane parameters in an incommensurate ratio. In these minerals, the two layers (Fig. 21) are a combination of a pseudo-quadratic layer (labelled Q) with a pseudo-hexagonal one (labelled H; Makovicky and Hyde, 1981). In general, the Q layer is a (100) slab of the $\mathrm{PbS} / \mathrm{NaCl}$ archetype, two to four atoms thick (e.g. 2 in cylindrite, 4 in franckeite), whereas the $\mathrm{H}$ layer is more variable, corresponding to different kinds of layer (i.e. $\mathrm{CdI}_{2}$-type, tetradymite-type or $\mathrm{NbS}_{2}$-type). The relative orientation of the $\mathrm{Q}$ and $\mathrm{H}$ layers depends on the relative sizes of their constitutive cations (Fig. 22).

Three members of the cylindrite group have recently been characterized structurally by means of a (3+2)-dimensional superspace approach: levyclaudite, $\sim \mathrm{Cu}_{3} \mathrm{~Pb}_{8} \mathrm{Sn}_{7}(\mathrm{Bi}, \mathrm{Sb})_{3} \mathrm{~S}_{28}$ 


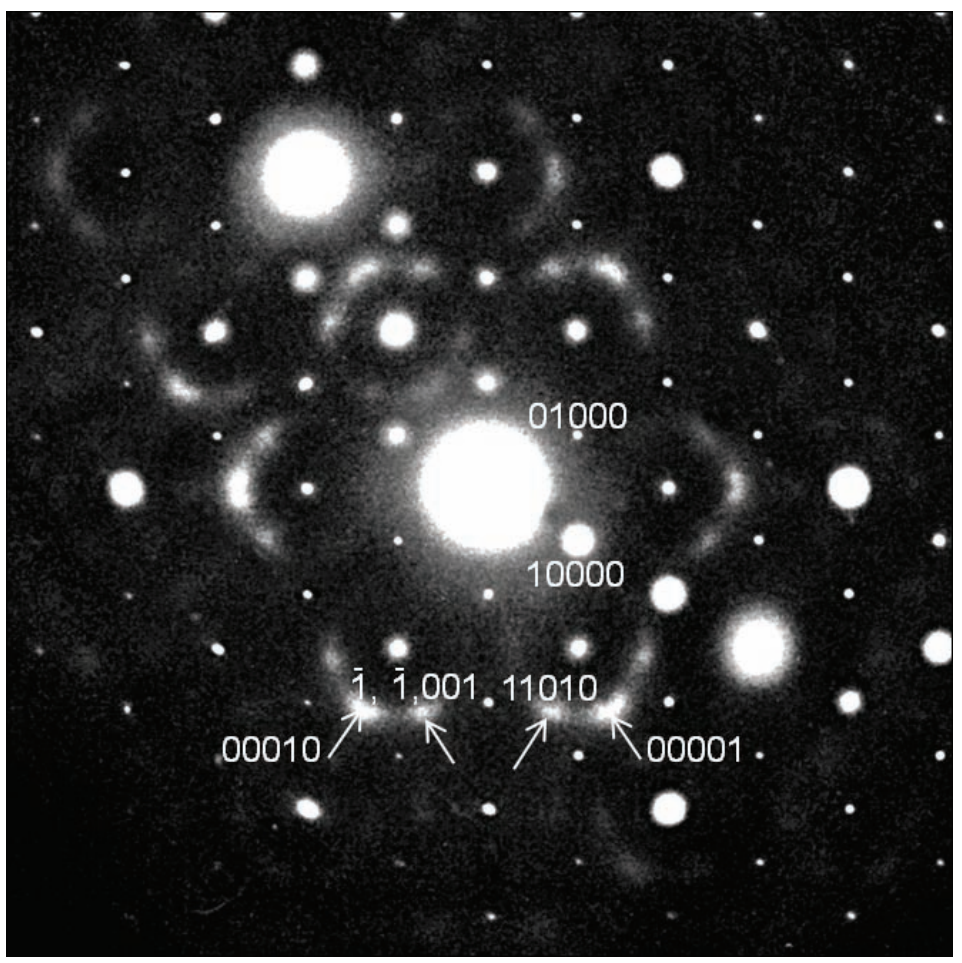

Fig. 18. The $\sim<001>$ zone axis electron diffraction pattern of a pearceite-Tac (Withers et al., 2008) indexed in standard composite modulated fashion using the set of five reciprocal space basis vectors $\left\{\mathbf{a}_{\mathrm{F}}{ }^{*}\right.$, $\mathbf{b}_{\mathrm{F}} *, \mathbf{c}_{\mathrm{F}}^{*}, \mathbf{a}_{\mathrm{Ag}} *$ and $\left.\mathbf{b}_{\mathrm{Ag}} *\right\}$.

(Evain et al., 2006c), synthetic $\mathrm{Sn}_{31.52} \mathrm{Sb}_{6.23} \mathrm{Fe}_{3.12} \mathrm{~S}_{59.12}$ (Makovicky et al., 2008) and franckeite, $\mathrm{Pb}_{21.7} \mathrm{Sn}_{9.3} \mathrm{Fe}_{4.0} \mathrm{Sb}_{8.1} \mathrm{~S}_{56.9}$ (Makovicky et al., 2011). All of these authors have pointed out that this family of misfit-layer compounds results from the combination of two heavily modulated triclinic $\mathrm{Q}$ and $\mathrm{H}$ subsystems with a common $\mathbf{q}$ wavevector and only one shared reciprocal axis (stacking direction). The differences and similarities among the three compounds are too complex to be outlined briefly in a general review but are related to the relationships between layer match and the modulation vector, divergence of layer stacking of the two components, as well as the pronounced disorder of the Q component.

\section{Naturally occurring quasicrystals}

\subsection{The case of icosahedrite}

Although there is an increasing number of syntheses and careful characterizations of new quasicrystals, there still has not been a general consensus concerning the status of quasicrystals as a fundamental state of matter. These materials were also considered too 

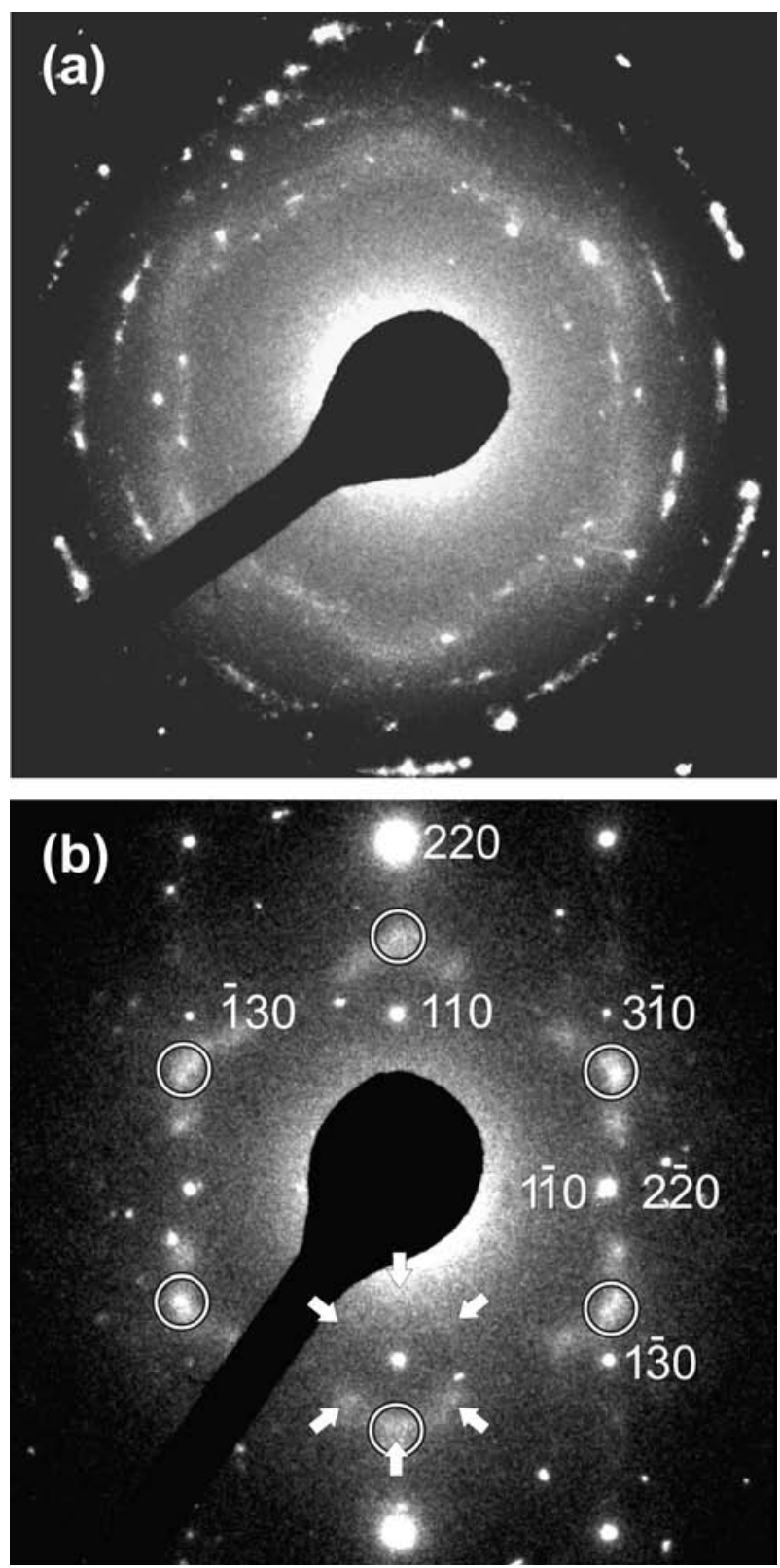

Fig. 19. Electron diffraction pattern of a thick crystal portion of cupropearceite which shows: (a) the dominant diffuse pseudo-hexagonal $\mathrm{Ag}^{+}$ion distribution; (b) the incommensurate satellite reflections of the $\mathrm{Ag}^{+}$ion distribution (arrows) with the $\mathrm{Ag}^{+}$sub-lattice emphasized (circle marks), along with the basic framework lattice diffraction (reproduced from Bindi et al. (2013) with the permission of the Mineralogical Society of America). 

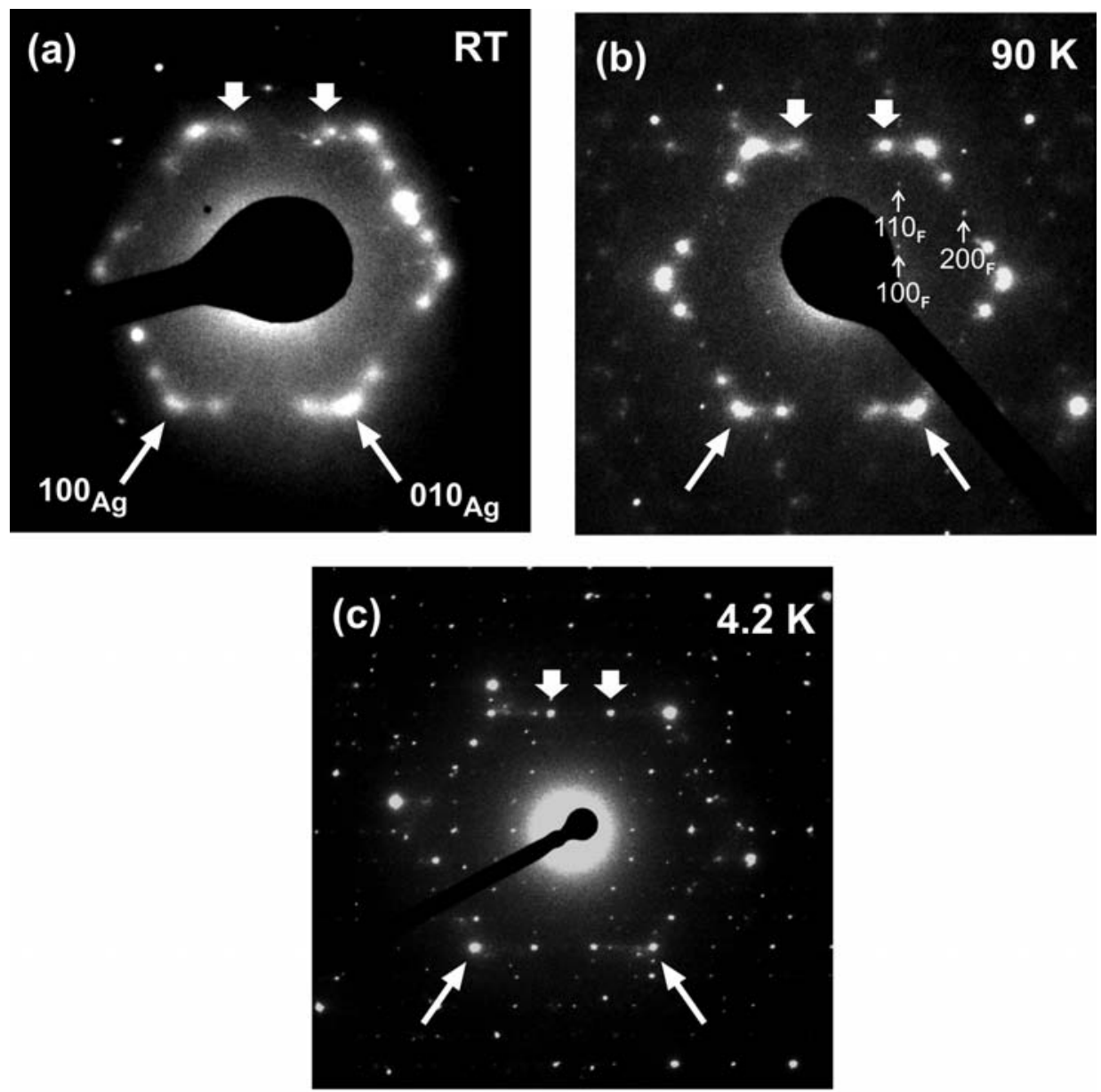

Fig. 20. Electron diffraction of the structure of cupropearceite dependent on temperature: (a) room temperature (RT); (b) $T=90 \mathrm{~K}$; (c) $T=4.2 \mathrm{~K}$. The composite structure consisting of the basic framework sub-structure (labelled with the subscript F) and the $\mathrm{Ag}^{+}$ion sub-structure (labelled with the subscript $\mathrm{Ag}$ ) undergoes an incommensurate-to-commensurate phase transformation between RT and $4.2 \mathrm{~K}$ (see satellites labelled by bold arrows) (reproduced from Bindi et al. (2013) with the permission of the Mineralogical Society of America).

elaborate to be stable states of matter given the fact that all ground states are crystalline. This led to an alternative view to explain quasicrystals: as formed by random tilings (arrangements of Penrose tiles without matching rules) with the icosahedral symmetry appearing for entropic reasons, although not energetically preferred (Henley, 1991). According to this picture, quasicrystals are inherently delicate, metastable oddities that may only be synthesized for ideal compositions and under highly controlled laboratory conditions. On the contrary, the original theory (construction of tilings with perfect 

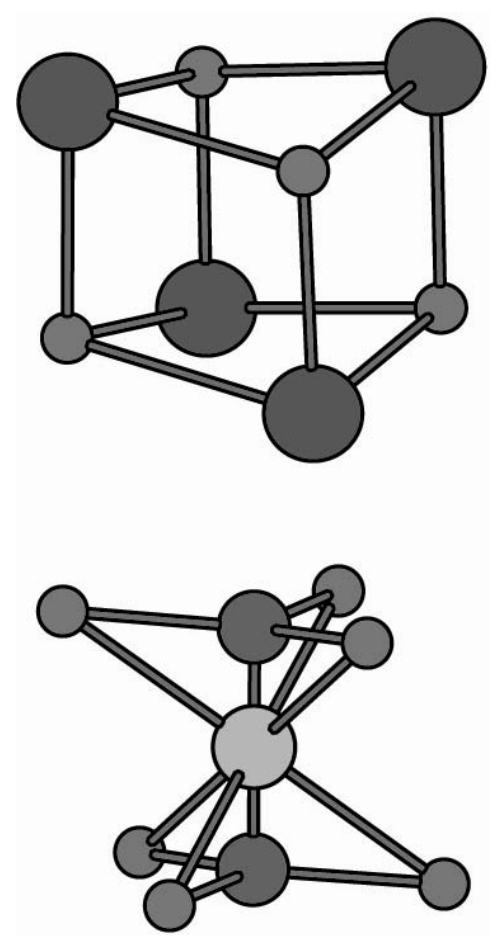

Fig. 21. Example of Q layer (with a distorted PbS-/ $\mathrm{NaCl}$-type structure) and $\mathrm{H}$ layer (with a $\mathrm{CdI}_{2}$-type structure) in levyclaudite (modified after Evain et $a l ., 2006 \mathrm{c})$. Spheres, with decreasing size, indicate $\mathrm{Pb} / \mathrm{Sb}, \mathrm{Sn}, \mathrm{Cu}$ and $\mathrm{S}$, respectively.

matching rules) considered quasicrystals as energetically stable and robust as crystals and forming even in conditions which were not ideal (Levine and Steinhardt, 1984).

In this context, it is clear that searching quasicrystals in nature could help to answer this question. If quasicrystals are energetically stable and robust as crystals, then it is conceivable that they formed under natural conditions, just like crystalline minerals. So, the question is: is it possible that quasicrystals formed through natural geological processes long before they were discovered in the laboratory?

After a decade-long search (Lu et al., 2001), in 2009, a new kind of mineral was discovered in a rock labelled "khatyrkite" catalogued as coming from the Khatyrka region of the Koryak mountains in the Chukotka autonomous okrug (district) on the northeastern part of the Kamchatka peninsula (Bindi et al., 2009b, 2011) belonging to the collections of the Museo di Storia Naturale of the Università degli Studi di Firenze (catalogue number $46407 / \mathrm{G}$ ). The mineral, a naturally formed quasicrystal, exhibits a distinct atomic arrangement with rotational symmetries incompatible for ordinary crystals. The first natural quasicrystal has been accepted officially by the Commission on New Minerals, Nomenclature and Classification of the International Mineralogical Association and named icosahedrite for the icosahedral symmetry of its atomic structure (Bindi et al., 2011). The mineral is classified as icosahedral (face-centred icosahedral symmetry) with diffraction peaks labelled by six indices (corresponding to the six basis vectors that define the reciprocal lattice). 


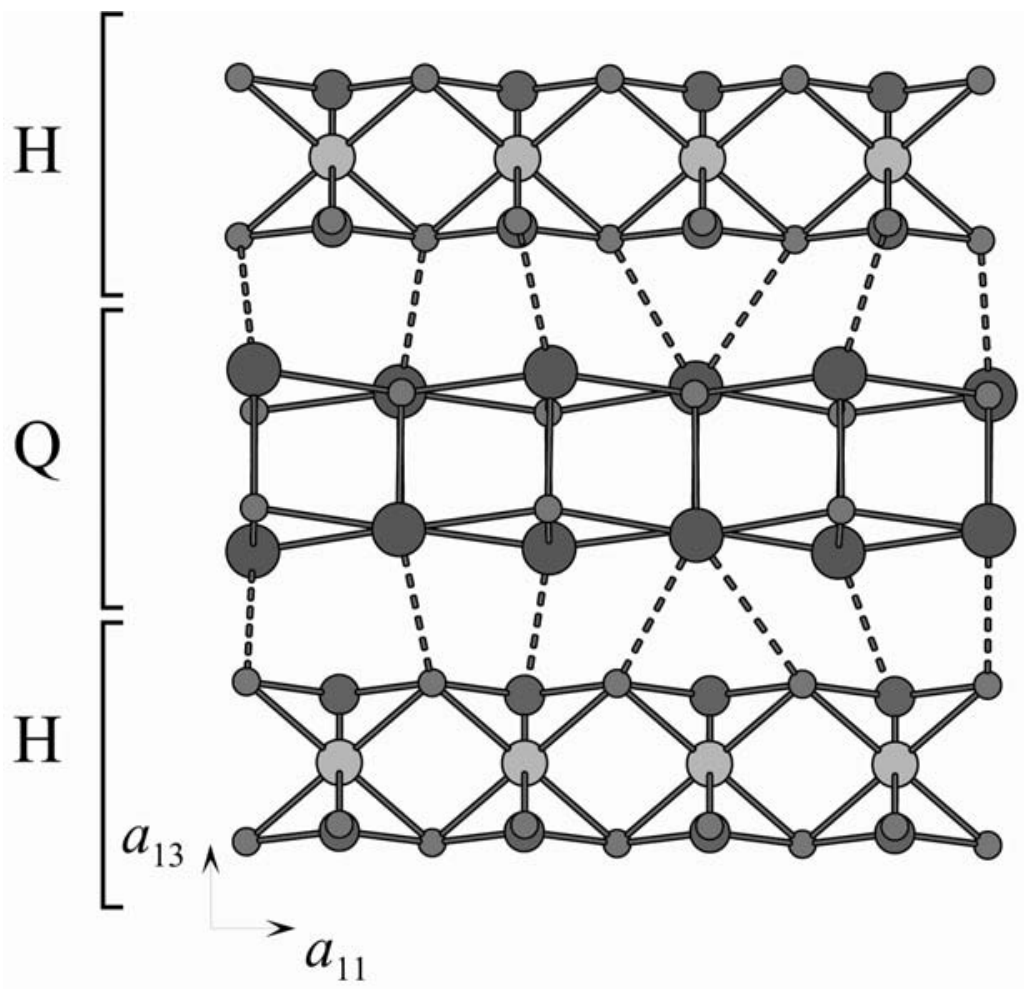

Fig. 22. Succession along the $a_{13}\left(a_{23}\right)$ axis of the $\mathrm{Q}$ and $\mathrm{H}$ layers in levyclaudite (modified after Evain et al., 2006c). The subscripts indicate the different subsystems and the different subcells (see Evain et al., $2006 \mathrm{c}$ for explanation). Broken lines indicate the two subsystem interactions (symbols as in Fig. 1.21).

To characterize the atomic structure of icosahedrite, several grains of the mineral were examined by transmission electron microscopy. The grains were found to be mostly homogeneous, with a stoichiometry close to $\mathrm{Al}_{63} \mathrm{Cu}_{24} \mathrm{Fe}_{13}$. The diffraction patterns consist of sharp peaks arranged in a quasi-periodic lattice with five-, three- and two-fold symmetry (Fig. 23), the characteristic signature of an icosahedral quasicrystal (e.g. Levine and Steinhardt, 1984; Bancel, 1991). In addition, the angles between the symmetry planes are consistent with icosahedral symmetry. For example, the angle between the two- and five-fold symmetry planes was $31.6(5)^{\circ}$, in excellent agreement with the ideal rotation angle between the two-fold and five-fold axes of an icosahedron [i.e. $\arctan (1 / \tau)=31.7^{\circ}$, where $\tau$ is the golden ratio defined as $(1+\sqrt{ } 5) / 2$ ].

The cubic lattice parameter (in six-dimensional notation) obtained with the XRD experiment for icosahedrite (Bindi et al., 2009b) can be written as $a_{6 \mathrm{D}}=12.64 \AA$ (Steurer and Deloudi, 2009), with probable space group $F m \overline{3} \overline{5}$. The six-dimensional $a$ parameter for the synthetic analogue of icosahedrite first synthesized by Tsai et al. (1987) is reported as $4.45 \AA$ and $\sim 6.31 \AA$ (Quiquandon et al., 1996; Quiquandon and Gratias, 2006). These values are $a_{6 \mathrm{D}} / \sqrt{ }(5 \tau)$ and $a_{6 \mathrm{D}} / 2$, respectively, of the value 
reported for icosahedrite by Bindi et al. (2009b); consequently, all the values are consistent, depending on the arbitrary choice of principal-axis length for the same $6 \mathrm{D}$ reciprocal lattice.

Interestingly, TEM and XRD experiments also demonstrated the high degree of structural perfection in icosahedrite with respect to the typical quasicrystals produced in the laboratory. Quasicrystals made by rapid quenching and/or embedded in a matrix of another phase, exhibit easily detectable phason strains (Levine et al., 1985; Lubensky et al., 1986). Phasons are hydrodynamic (gapless) modes that occur in incommensurate crystals and quasicrystals in addition to the usual phonon modes. If the atomic density $\rho(x)$ is decomposed into a sum of incommensurate density waves, a phason shift corresponds to uniform phase shifts between density waves the periods of which have an irrational ratio. A phason strain corresponds to a spatial gradient in the phase shift. According to Bancel (1991), at the atomic level, phason strains produce rearrangements of atoms relative to the ideal, ground state configuration that require diffusive motion to relax away, so the phason strains remain after solidification unless the sample is grown under a very carefully controlled protocol. In reciprocal space, the signature of phason strain is a systematic shift in the Bragg peak positions from the ideal by an amount that increases as the peak intensity decreases. The effect is easily observed by holding the diffraction pattern at a grazing angle and viewing down rows of peaks. The phason strain can be observed as deviations of the dimmer peaks from straight lines (Lubensky et al., 1986). The fact that icosahedrite shows no visible phason strain (Fig. 23) means either the mineral sample formed without phason strain in the first place, or subsequent annealing was sufficient for phason strains to relax away.

Beside the crystallographic description of the first naturally occurring quasicrystal, a puzzling, but, at the same time, very exciting aspect for geologists is the presence of metallic aluminium in the quasicrystal grains as well as some of the other mineral phases (i.e. khatyrkite, $\mathrm{CuAl}_{2}$, and cupalite, $\mathrm{CuAl}$ ) found in the rock hosted in the mineralogical collections of the Florence Museum (Bindi et al., 2009b, 2011). Indeed, aluminium normally oxidizes unless placed in a highly reducing environment, as is done in the laboratory or in industry. Hence, serious consideration had to be given to the possibility that the sample is slag or an accidental byproduct of some anthropogenic process. Some of the significant evidence against this possibility includes: the remote, uninhabited region where the sample was found being very far from any industry; the presence of typical rock-forming minerals (forsterite and diopside) in direct contact with metal alloys; the absence of glass or bubbles; unusual zoning of phosphorus and chromium in the forsterite grains (Bindi et al., 2012; Steinhardt and Bindi, 2012); the concentration of nickel in the forsterite but not in the metal alloys (Bindi et al., 2012); and, most importantly, grains of quasicrystal trapped within stishovite (Bindi et al., 2012; Steinhardt and Bindi, 2012). Each of these features is individually inconsistent with an anthropogenic origin for different reasons; collectively, they make an overwhelming case that some natural process led to the formation of the rock.

As the quasicrystal and the other metallic aluminium alloys cannot be explained by any conventional geological processes, determining how they formed has been both 

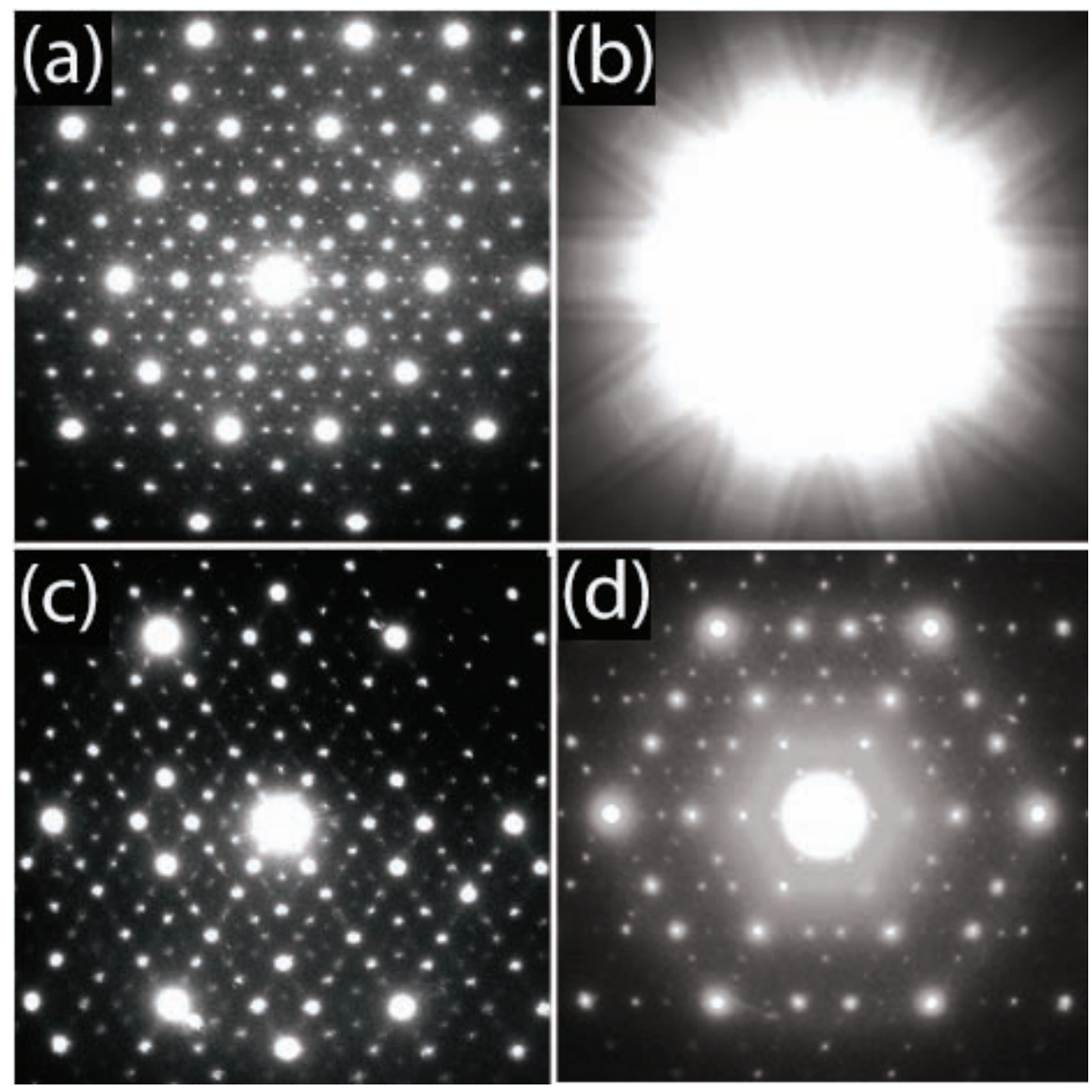

Fig. 23. The five-fold (a), two-fold (c) and three-fold (d) electron diffraction patterns for icosahedrite. The patterns correspond perfectly, up to experimental resolution, with the five-, two-, and three-fold patterns predicted for a face-centred icosahedral quasicrystal. Figure (b) shows the convergent beam (Kikuchi) diffraction pattern obtained along the five-fold axis, providing further physical evidence of the symmetry and high degree of translational order (reproduced from Bindi et al. (2011) with the permission of the Mineralogical Society America).

challenging and important. The discovery of the stishovite grain noted above (Bindi et al., 2012; Steinhardt and Bindi, 2012) indicated that the mineral formed at pressures that occur under exotic conditions, either very deep under the surface of the Earth, near the boundary between core and mantle, or in space, through the collisions of meteors and asteroids. To distinguish between the two possibilities, a series of ion-probe experiments that measure the ratio of oxygen isotopes was carried out (Bindi et al., 2012; MacPherson et al., 2013). The results were unmistakable: the oxygen isotopes matched precisely the known abundances of the carbonaceous chondrites, among the oldest meteorites to have formed in our solar system. 
Establishing that the sample is indeed natural took nearly 2 years of laboratory (Bindi et al., 2012) and detective work, and, ultimately, a geological expedition to the Koryak Mountains of Chukotka in far eastern Russia to find additional samples. The extraordinary story, recounted elsewhere (Bindi and Steinhardt, 2012; Steinhardt and Bindi, 2012) established that the quasicrystal and the rock containing it are definitely part of a carbonaceous chondrite, with calcium aluminium inclusions, that dates back 4.5 Gya to the formation of the solar system (MacPherson et al., 2013). The new meteorite find has been named Khatyrka (MacPherson et al., 2013). The name derives from the Khatyrka river, which is one of the main rivers draining the Koryak Mountains. That river is also the basis for the name of the mineral, khatyrkite, which gives an added symmetry to the meteorite name. Khatyrka has been approved by the Nomenclature Committee of the Meteoritical Society and representative specimens have been deposited at the U.S. National Museum of Natural History, Smithsonian Institution, Washington D.C.

In the Khatyrka meteoritic fragments recovered during the expedition, which present a range of evidence indicating that an impact shock generated a heterogeneous distribution of pressures and temperatures in which some portions of the meteorite reached at least $5 \mathrm{GPa}$ and $1200^{\circ} \mathrm{C}$ (Hollister et al., 2014), the second natural quasicrystal has been found (Bindi et al., 2015a). The quasicrystal has the composition $\mathrm{Al}_{71} \mathrm{Ni}_{24} \mathrm{Fe}_{5}$ and is the first known natural quasicrystal with decagonal symmetry, a periodic stacking of layers containing quasiperiodic atomic arrangements with ten-fold symmetry. The mineral and its name have been approved by the Commission on New Minerals, Nomenclature and Classification of the International Mineralogical Association (Bindi et al., 2015b). As already observed for icosahedrite (Bindi et al., 2009b, 2011), decagonite exhibits a high degree of structural perfection, particularly the absence of significant phason strains. This is unusual because such a high degree of perfection was obtained in a quasicrystal intergrown with other phases under conditions that are clearly far from equilibrium and not under controlled laboratory conditions. We think that either the mineral samples formed without phason strain in the first place, or subsequent annealing was sufficient for phason strains to relax away.

So, what is the significance of the discovery of the first minerals with forbidden symmetry in Nature? In geology, the discovery of natural quasicrystals has opened a new chapter in the study of mineralogy, forever altering the conventional classification of mineral forms. In condensed-matter physics, the discovery has pushed back the age of the oldest quasicrystals by orders of magnitude and has had an impact on our view of how difficult it is for quasicrystals to form. Finding natural quasicrystals has also been a way of studying quasicrystal stability over annealing times and conditions not accessible in the laboratory. Identifying materials that form quasicrystals has always relied significantly on trial-and-error and serendipity, and searching through nature has proved to be an effective complement to laboratory methods. Finally, the discovery has suggested new geological or extra-terrestrial processes of formation. 


\section{Conclusions}

The field of aperiodic crystallography is now well established. The discovery of natural minerals covering all the variants of aperiodic structures, i.e. incommensurate and composite structures as well as quasicrystals is definite proof of the stability of their structures over a long period of time. The theory of superspace including the symmetry properties is now commonly used to resolve and describe aperiodic structures.

The recent development of intensive synchrotron sources along with the rapid evolution of two-dimensional detectors has led to the discovery of several incommensurate crystals, and indicated that incommensurability cannot be ignored in any field of solid-state sciences. Indeed, incommensurate modulation has been found in almost all families of structures that include synthetic inorganic and organic compounds, as well as proteins. Modulated structures have also been found widely in various minerals. However, structural studies of naturally occurring incommensurately modulated structures, using the superspace formalism, are few in number. Studies limited to electron diffraction are not sufficient because accurate knowledge of the modulation functions is a prerequisite for understanding the crystal chemistry of incommensurate crystals. The structural analysis of modulated minerals is still very underdeveloped, and is probably one of the major future challenges in the field of crystallography.

\section{Acknowledgements}

The authors give special thanks to Paola Bonazzi, Silvio Menchetti (Università di Firenze, Italy), Alla Arakcheeva (Swiss Federal School of Technology, Switzerland), Vladimir Dmitrienko (Shubnikov Institute of Crystallography, Russia), Michel Evain (Université de Nantes, France), Michal Dušek, Vaclav Petř́iček (Institute of Physics, Czech Republic), Ray Withers (Australian National University, Australia), Andreas Schaper (Philipps University, Germany) Lincoln S. Hollister, Paul J. Steinhardt, Nan Yao (Princeton University, USA), Peter J. Lu, Will Steinhardt (Harvard University, USA), Glenn MacPherson (Smithsonian Institution, USA), Christopher Andronicos (Purdue University, USA), Vadim Distler, Marina Yudovskaya (IGEM, Russia), Alexander Kostin (BHP Billiton, USA), Valery Kryachko (Voronezh, IGEM) and Michael Eddy (MIT, USA) for fruitful discussions and for production of some of the data reported here. The authors also appreciate helpful reviews by Vaclav Petř́iček and Stefano Merlino.

\section{References}

Angel, R.J., McMullan, R.K. and Prewitt, C.T. (1991) Substructure and superstructure of mullite by neutron diffraction. American Mineralogist, 76, 332-342.

Angel, R.J., Gatta, G.D., Boffa-Ballaran, T. and Carpenter, M. (2008) The mechanism of coupling in the modulated structure of nepheline. The Canadian Mineralogist, 46, 1465-1476.

Arakcheeva, A., Bindi, L., Pattison, P., Meisser, N., Chapuis, G. and Pekov, I. (2010) The incommensurately modulated structures of natural natrites at 120 and $293 \mathrm{~K}$ from synchrotron X-ray data. American Mineralogist, 95, 574-581.

Arakcheeva, A. and Chapuis, G. (2005) A reinterpretation of the phase transitions in $\mathrm{Na}_{2} \mathrm{CO}_{3}$. Acta 
Crystallographica, B61, 601-607.

Arakcheeva, A. and Chapuis, G. (2008) Capabilities and limitations of a (3+d)-dimensional incommensurately modulated structure as a model for the derivation of an extended family of compounds: example of the scheelite-like structures. Acta Crystallographica B64, 12-25.

Armbruster, T., Röthlisberger, F. and Seifert, F. (1990) Layer topology, stacking variation, and site distortion in melilite-related compounds in the system $\mathrm{CaO}-\mathrm{ZnO}-\mathrm{GeO}_{2}-\mathrm{SiO}_{2}$. American Mineralogist, 75, 847-858.

Bagautdinov, B., Hagiya, K., Noguchi, S., Ohmasa, M., Ikeda, N., Kusaka, K. and Iishi, K. (2002) Lowtemperature studies on the two-dimensional modulations in åkermanite-type crystals: $\mathrm{Ca}_{2} \mathrm{MgSi}_{2} \mathrm{O}_{7}$ and $\mathrm{Ca}_{2} \mathrm{ZnSi}_{2} \mathrm{O}_{7}$. Physics and Chemistry of Minerals, 29, 346-350.

Balzuweit, K., Hovestad, A., Meekes, H. and de Boer, J.L. (1993) The temperature and composition dependence of the modulation wave vector of incommensurate calaverite. Journal of Crystal Growth, 131, 518-532.

Bancel, P.A. (1991) Order and disorder in icosahedral alloys. Pp. 17-56 in: Quasicrystals: The State of the Art (D. DiVincenzo and P.J. Steinhardt, editors). World Scientific, Singapore.

Bindi, L. (2008) Commensurate-incommensurate phase transition in muthmannite, $\mathrm{AuAgTe}_{2}$ : First evidence of a modulated structure at low-temperature. Philosophical Magazine Letters, 88, 533-541.

Bindi, L. and Steinhardt, P.J. (2012) The discovery of the first natural quasicrystal. A new era for mineralogy? Elements, 8, 13-14.

Bindi, L., Bonazzi, P., Dušek, M., Petříček, V. and Chapuis, G. (2001a) Five dimensional structure refinement of natural melilite $\left(\mathrm{Ca}_{1.89} \mathrm{Sr}_{0.01} \mathrm{Na}_{0.08} \mathrm{~K}_{0.02}\right)\left(\mathrm{Mg}_{0.92} \mathrm{Al}_{0.08}\right)\left(\mathrm{Si}_{1.98} \mathrm{Al}_{0.02}\right) \mathrm{O}_{7}$. Acta Crystallographica, B57, 739-746.

Bindi, L., Czank, M., Röthlisberger, F. and Bonazzi, P. (2001b) Hardystonite from Franklin Furnace: a natural modulated melilite. American Mineralogist, 86, 747-751.

Bindi, L., Evain, M., Pradel, A., Albert, S., Ribes, M. and Menchetti, S. (2006a) Fast ionic conduction character and ionic phase-transitions in disordered crystals: The complex case of the minerals of the pearceitepolybasite group. Physics and Chemistry of Minerals, 33, 677-690.

Bindi, L., Evain, M. and Menchetti, S. (2006b) Temperature dependence of the silver distribution in the crystal structure of natural pearceite, $(\mathrm{Ag}, \mathrm{Cu})_{16}(\mathrm{As}, \mathrm{Sb})_{2} \mathrm{~S}_{11}$. Acta Crystallographica, B62, 212-219.

Bindi, L., Evain, M. and Menchetti, S. (2006c) Complex twinning, polytypism and disorder phenomena in the crystal structures of antimonpearceite and arsenpolybasite. The Canadian Mineralogist, 45, 321-333.

Bindi, L., Dušek, M., Petř́íček, V. and Bonazzi, P. (2006d) Superspace-symmetry determination and multidimensional refinement of the incommensurately modulated structure of a natural fresnoite. Acta Crystallographica, B62, 1031-1037.

Bindi, L., Evain, M., Spry, P.G., Tait, K.T. and Menchetti, S. (2007a) Structural role of copper in the minerals of the pearceite-polybasite group: The case of the new minerals cupropearceite and cupropolybasite. Mineralogical Magazine, 71, 641-650.

Bindi, L., Evain, M., Spry, P.G. and Menchetti, S. (2007b) The pearceite-polybasite group of minerals: Crystal chemistry and new nomenclature rules. American Mineralogist, 92, 918-925.

Bindi, L., Arakcheeva, A. and Chapuis, G. (2009a) The role of silver on the stabilization of the incommensurately modulated structure in calaverite, AuTe 2 . American Mineralogist, 94, 728-736.

Bindi, L., Steinhardt, P.J., Yao, N. and Lu, P.J. (2009b) Natural quasicrystals. Science, 324, 1306-1309.

Bindi, L., Steinhardt, P.J., Yao, N. and Lu, P.J. (2011) Icosahedrite, $\mathrm{Al}_{63} \mathrm{Cu}_{24} \mathrm{Fe}_{13}$, the first natural quasicrystal. American Mineralogist, 96, 928-931.

Bindi, L., Eiler, J.M., Guan, Y., Hollister, L., MacPherson, G.J., Steinhardt, P.J. and Yao, N. (2012) Evidence for the extra-terrestrial origin of a natural quasicrystal. Proceedings of the National Academy of Sciences, USA, 109, 1396-1401.

Bindi, L., Schaper, A.K., Kurata, H. and Menchetti, S. (2013) The composite modulated structure of cupropearceite and cupropolybasite and its behavior toward low temperature. American Mineralogist, 98, 1279-1284.

Bindi, L., Yao, N., Lin, C., Hollister, L.S., Andronicos, C.L., Distler, V.V., Eddy, M.P., Kostin, A., Kryachko, V., MacPherson, G.J., Steinhardt, W.M., Yudovskaya, M. and Steinhardt, P.J. (2015a) Natural quasicrystal with decagonal symmetry. Scientific Reports, 5, 9111.

Bindi, L., Yao, N., Lin, C., Hollister, L.S., Andronicos, C.L., Distler, V.V., Eddy, M.P., Kostin, A., Kryachko, V., MacPherson, G.J., Steinhardt, W.M., Yudovskaya, M. and Steinhardt, P.J. (2015b) Decagonite, 
$\mathrm{Al}_{71} \mathrm{Ni}_{24} \mathrm{Fe}_{5}$, a quasicrystal with decagonal symmetry from the Khatyrka CV3 carbonaceous chondrite. American Mineralogist, 100, 2340-2343.

Bolotina, N.B. (2006) Isotropic lazurite: A cubic single crystal with an incommensurate three-dimensional modulation of the structure. Crystallography Reports, 51, 968-976.

Bolotina, N.B., Rastsvetaeva, R.K., Sapozhnikov, A.N., Kashaev, A.A., Schönleber, A. and Chapuis, G. (2003a) Incommensurately modulated structure of isotropic lazurite as a product of twinning of two-dimensionally modulated domains. Crystallography Reports, 48, 721-727.

Bolotina, N.B., Rastsvetaeva, R.K., Sapozhnikov, A.N., Kashaev, A.A., Schönleber, A. and Chapuis, G. (2003b) Three-dimensionally modulated incommensurate crystal structure of lazurite from the Baikal region. Crystallography Reports, 48, 8-11.

Bolotina, N.B., Rastsveteva, R.K., Chapuis, G., Schönleber, A., Sapozhnikov, A.N. and Kashaev, A.A. (2004) On the symmetry of optically isotropic modulated lazurites from the Baikal region. Ferroelectrics, 305, 95-98.

Bolotina, N.B., Rastsvetaeva, R.K. and Sapozhnikov, A.N. (2006) Average structure of incommensurately modulated monoclinic lazurite. Crystallography Reports, 51, 589-595.

Brouns, E., Visser, J.W. and de Wolff, P.M. (1964) An anomaly in the crystal structure of $\mathrm{Na}_{2} \mathrm{CO}_{3}$. Acta Crystallographica, A17, 614.

Buseck, P.R. and Cowley, J.M. (1983) Modulated and intergrowth structures in minerals and electron microscope methods for their study. American Mineralogist, 68, 18-40.

Caracas, R. and Gonze, X. (2001) Ab initio determination of the valence electron distribution in the average structure of the incommensurately modulated calaverite AuTe A $_{2}$ Acta Crystallographica, B57, 633-637.

Carter, M.L. and Withers, R.L. (2004) An electron and X-ray diffraction study of the compositely modulated barium nickel hollandite $\mathrm{Ba}_{x}\left(\mathrm{Ni}_{x} \mathrm{Ti}_{8-x}\right) \mathrm{O}_{16}, 1.16<x<1.32$, solid solution. Zeitschrift für Kristallographie, 219, $763-767$.

Chapuis, G. (2003) Crystallographic excursion in superspace. Crystal Engineering, 6, 187-195.

Dam, B. and Janner, A. (1986) A Superspace approach to the structure and morphology of tetramethylammonium tetrachlorozincate, $2 \mathrm{C}_{4} \mathrm{H}_{12} \mathrm{~N}^{+}$. $\mathrm{ZnCl}_{4}^{2-}$. Acta Crystallographica, B42, 69-77.

Dam, B., Janner, A. and Donnay, J.D.H. (1985) Incommensurate morphology of calaverite (AuTe $)_{2}$ crystals. Physical Review Letters, 55, 2301-2304.

Dušek, M., Chapuis, G., Meyer, M. and Petř́iček, V. (2003) Sodium carbonate revisited. Acta Crystallographica, B59, 337-352.

Edenharter, A., Koto, K. and Nowacki, W. (1971) Uber Pearceit, Polybasit und Binnit. Neues Jahrbuch für Mineralogie Monatshefte, 1971, 337-341.

Evain, M., Bindi, L. and Menchetti, S. (2006a) Structure and phase transition in the Se-rich variety of antimonpearceite, $\left(\mathrm{Ag}_{14.67} \mathrm{Cu}_{1.20} \mathrm{Bi}_{0.01} \mathrm{~Pb}_{0.01} \mathrm{Zn}_{0.01} \mathrm{Fe}_{0.03}\right)_{15.93}\left(\mathrm{Sb}_{1.86} \mathrm{As}_{0.19}\right)_{2.05}\left(\mathrm{~S}_{8.47} \mathrm{Se}_{2.55}\right)_{11.02}$. Acta Crystallographica, B62, 768-774.

Evain, M., Bindi, L. and Menchetti, S. (2006b) Structural complexity in minerals: twinning, polytypism and disorder in the crystal structure of polybasite, $(\mathrm{Ag}, \mathrm{Cu})_{16}(\mathrm{Sb}, \mathrm{As})_{2} \mathrm{~S}_{11}$. Acta Crystallographica, B62, 447-456.

Evain, M., Petříček, V., Moëlo, Y. and Maurel, C. (2006c) First (3 + 2)-dimensional superspace approach to the structure of levyclaudite-(Sb), a member of the cylindrite-type minerals. Acta Crystallographica, B62, $775-789$.

Friese, K., Grzechnik, A., Petř́iček, V., Schönleber, A., van Smaalen, S. and Morgenroth, W. (2011) Modulated structure of nepheline. Acta Crystallographica, B67, 18-29.

Frondel, C. (1963) Isodimorphism of the polybasite and pearceite series. American Mineralogist, 48, 565-572.

Ghent, F.A. (1861) Calaverite. American Journal of Science, 45, 314-317.

Goldschmidt, V., Palache, C. and Peacock, M. (1931) Ueber Calaverit. Neues Jahrbuch für Mineralogie Monatshefte, 63, 1-58.

Guinier, A., Bokij, G.B., Boll-Dornberger, K., Cowley, J.M., Durovic, S., Jagodzinski, H., Krishna, P., de Wolff, P.M., Zvyagin, B.B., Cox, D.E., Goodman, P., Hahn, Th., Kuchitsu, K. and Abrahams, S.C. (1984) Nomenclature of polytype structures. Acta Crystallographica, A40, 399-404.

Hagiya, K., Ohmasa, M. and Iishi, K. (1993) The modulated structure of synthetic Co-åkermanite, $\mathrm{Ca}_{2} \mathrm{CoSi}_{2} \mathrm{O}_{7}$. Acta Crystallographica, B49, 172-179.

Hagiya, K., Kusaka, K., Ohmasa, M. and Iishi, K. (2001) Commensurate structure of $\mathrm{Ca}_{2} \mathrm{CoSi}_{2} \mathrm{O}_{7}$, a new 
twinned orthorhombic structure. Acta Crystallographica, B57, 271-277.

Hall, H.T. (1967) The pearceite and polybasite series. American Mineralogist, 52, 1311-1321.

Harris, D.C., Nuffield, E.W. and Frohberg, M.H. (1965) Studies of mineral sulphosalts: XIX-Selenian polybasite. The Canadian Mineralogist, 8, 172-184.

Hassan, I. (2000) Transmission electron microscopy and differential thermal studies of lazurite polymorphs. American Mineralogist, 85, 1383-1389.

Hassan, I. and Buseck, P.R. (1989) Incommensurate-modulated structure of nosean, a sodalite-group mineral. American Mineralogist, 74, 394-410.

Hassan, I. and Buseck, P.R. (1992) The origin of the superstructure and modulations in cancrinite. The Canadian Mineralogist, 30, 49-59.

Hassan, I., Antao, S.M. and Parise, J.B. (2004) Haüyne: phase transition and high-temperature structures obtained from synchrotron radiation and Rietveld refinements. Mineralogical Magazine, 68, 499-513.

Heaney, P.J. and Veblen, D.R. (1991) Observations of the $\alpha-\beta$ phase transition in quartz: A review of imaging and diffraction studies and some new results. American Mineralogist, 76, 1018-1032.

Hemingway, B.S., Evans, Jr. H.T., Nord, G.L. Jr., Haselton, H.T. Jr., Robie, R.A. and McGee, J.J. (1986) Åkermanite: phase transitions in heat capacity and thermal expansion, and revised thermodynamic data. The Canadian Mineralogist, 24, 425-434.

Henley, C. (1991) Random tiling models. Pp. 429-524 in: Quasicrystals: the State of the Art (D. DiVincenzo and P.J. Steinhardt, editors). World Scientific, Singapore.

Hollister, L.S., Bindi, L., Yao, N., Poirier, G.R., Andronicos, C.L., MacPherson, G.J., Lin, C., Distler, V.V., Eddy, M.P., Kostin, A., Kryachko, V., Steinhardt, W.M., Yudovskaya, M., Eiler, J.M., Guan, Y., Clarke, J.J. and Steinhardt, P.J. (2014) Impact-induced shock and the formation of natural quasicrystals in the early solar system. Nature Communications, 5: 3040 doi:10.1038/ncomms5040.

Höche, T., Rüssel, C. and Neumann, W. (1999) Incommensurate modulations in $\mathrm{Ba}_{2} \mathrm{TiSi}_{2} \mathrm{O}_{8}, \mathrm{Sr}_{2} \mathrm{TiSi}_{2} \mathrm{O}_{8}$ and $\mathrm{Ba}_{2} \mathrm{TiGe}_{2} \mathrm{O}_{8}$. Solid State Communications, 110, 651-656.

Janner, A. and Dam, B. (1989) The morphology of calaverite $\left(\mathrm{AuTe}_{2}\right)$ from data of 1931 - solution of an old problem of rational indexes. Acta Crystallographica, A45, 115-123.

Janssen, T., Janner, A., Looijenga-Vos, A. and Wolff de, P.M. (1992) Incommensurate and commensurate modulated structures. International Tables for X-ray Crystallography, Vol. C, p. 899-937. Kluwer Academic Publishers, Dordrecht, The Netherlands.

Janssen, T., Chapuis, G. and de Boissieu, M. (2007) Aperiodic Crystals: From Modulated Phases to Quasicrystals. Oxford University Press, Oxford, UK.

Jia, Z.H., Schaper, A.K., Massa, W., Treutmann, W. and Rager, H. (2006) Structure and phase transitions in $\mathrm{Ca}_{2} \mathrm{CoSi}_{2} \mathrm{O}_{7}-\mathrm{Ca}_{2} \mathrm{ZnSi}_{2} \mathrm{O}_{7}$ solid-solution crystals. Acta Crystallographica, B62, 547-555.

Kalning, M., Dorna, V., Press, W., Kek, S. and Boysen, H. (1997) Profile analysis of the superlattice reflections in labradorite. Zeitschrift für Kristallogrographie, 212, 545-549.

Korekawa, M. (1967) Theorie der satellitenreflexe. Hohen Naturwissenschaftlichen Fakultät, p. 153. LudwigsMaximilians-Universität, Munich.

Krutzen, B.C.H. and Inglesfield, J.E. (1990) First-principles electronic structure calculations for incommensurately modulated sylvanite. Journal of Physics: Condensed Matter, 2, 4829-4848.

Lazic, B., Armbruster, T., Chopin, C., Grew, E.S., Baronnet, A. and Palatinus, L. (2014) Superspace description of wagnerite-group minerals $(\mathrm{Mg}, \mathrm{Fe}, \mathrm{Mn})_{2}\left(\mathrm{PO}_{4}\right)(\mathrm{F}, \mathrm{OH})$. Acta Crystallographica, B70, 243-258.

Levine, D. and Steinhardt, P.J. (1984) Quasicrystals: A new class of ordered structures. Physical Review Letters, 53, 2477-2480.

Levine, D., Lubensky, T.C., Ostlund, S., Ramaswamy, A. and Steinhardt, P.J. (1985) Elasticity and defects in pentagonal and icosahedral quasicrystals. Physical Review Letters, 54, 1520-1523.

Li, F. and Franzen, H.F. (1996) Ordering, incommensuration, and phase transitions in pyrrhotite: Part II: A hightemperature X-ray powder diffraction and thermomagnetic study. Journal of Solid State Chemistry, 126, $108-120$.

Lu, P.J., Deffeyes, K., Steinhardt, P.J. and Yao, N. (2001) Identifying and indexing icosahedral quasicrystals from powder diffraction patterns. Physical Review Letters, 87, 275507-1-275507-4.

Lubensky, T.C., Socolar, J.E.S., Steinhardt, P.J., Bancel, P.A. and Heiney, P.A. (1986) Distortion and peak 
broadening in quasicrystal diffraction patterns. Physical Review Letters, 57, 1440-1443.

MacPherson, G.J., Andronicos, C., Bindi, L., Distler, V.V., Eddy, M., Eiler, J., Guan, Y., Hollister, L.S., Kostin, A., Kryachko, V., Steinhardt, W., Yudovskaya, M. and Steinhardt, P.J. (2013) Khatyrka, a new CV3 find from the Koryak Mountains, Eastern Russia. Meteoritics and Planetary Science, 48, 1499-1514

Makovicky, E. and Hyde, B.G. (1981) Non-commensurate (misfit) layer structures. Inorganic Chemistry, 46, $101-170$.

Makovicky, E. and Hyde, B.G. (1992) Incommensurate, two-layer structures with complex crystal chemistry: Minerals and related synthetics. Materials Science Forum, 100-101, 1-100.

Makovicky, E., Petříček, V., Dušek, M. and Topa, D. (2008) Crystal structure of a synthetic tin-selenium representative of the cylindrite structure type. American Mineralogist, 93, 1787-1798.

Makovicky, E., Petrríček, V., Dušek, M. and Topa, D. (2011) The crystal structure of franckeite, $\mathrm{Pb}_{21.7} \mathrm{Sn}_{9.3} \mathrm{Fe}_{4.0} \mathrm{Sb}_{8.1} \mathrm{~S}_{56.9}$. American Mineralogist, 96, 1686-1702.

Markgraf, S.A. and Bhalla, A.S. (1989) Low temperature phase transition in $\mathrm{Ba}_{2} \mathrm{TiGe}_{2} \mathrm{O}_{8}$. Phase Transitions, 18 , $55-76$.

Markgraf, S.A., Randall, C.A., Bhalla, A.S. and Reeder, R.J. (1990) Incommensurate phase in $\mathrm{Ba}_{2} \mathrm{TiGe}_{2} \mathrm{O}_{8}$. Solid State Communications, 75, 821-824.

Minčeva-Stefanova, I., Bonev, I. and Punev, L. (1979) Pearceite with an intermediate unit cell - first discovery in nature. Geokhimiya, Mineralogiya I Petrologiya, 11, 13-34 (in Bulgarian).

Morozov, V.A., Arakcheeva, A.V., Konovalova, V.V., Pattison, P., Chapuis, G., Lebedev, O.I., Fomichev, V.V. and Van Tendeloo, G. (2010) $\mathrm{LiZnNb}_{4} \mathrm{O}_{11.5}$ : A novel oxygen deficient compound in the Nb-rich part of the $\mathrm{Li}_{2} \mathrm{O}-\mathrm{ZnO}-\mathrm{Nb}_{2} \mathrm{O}_{5}$ system. Journal of Solid State Chemistry, 183, 408-418.

Norén, L., Withers, R.L. and Brink, F.J. (2005) Where are the Sn atoms in $\mathrm{LaSb}_{2} \mathrm{Sn}_{\mathrm{x}}, 0.1 \leqslant \mathrm{x} \leqslant \sim 0.75$ ? Journal of Solid State Chemistry, 178, 2133-2143.

Oszlányi, G. and Sütó, A. (2004) Ab initio structure solution by charge flipping. I. Acta Crystallographica, A60, $134-141$.

Oszlányi, G. and Sütó, A. (2005) Ab initio structure solution by charge flipping. II. Use of weak reflections. Acta Crystallographica, A61, 147-152.

Penfield, S.L. and Ford, W.E. (1902) Ueber den Calaverit. Zeitschrift für Kristallographie, 35, 430-451.

Petř́iček, V., Dušek, M. and Palatinus, L. (2006) Jana2006. The crystallographic computing system. Institute of Physics, Praha, Czech Republic.

Pring, A., Williams, T. and Withers, R. (1993) Structural modulation in sartorite: An electron microscope study. American Mineralogist, 78, 619-626.

Pryde, A.K.A. and Dove, M.T. (1998) On the sequence of phase transitions in tridymite. Physics and Chemistry of Minerals, 26, 171-179.

Quiquandon, M. and Gratias, D. (2006) Unique six-dimensional structural model for Al-Pd-Mn and Al-Cu-Fe icosahedral phases. Physical Review, B74, article \#214205.

Quiquandon, M., Quivy, A., Devaud, J., Faudot, F., Lefebvre, S., Bessière, M. and Calvayrac, Y. (1996) Quasicrystal and approximant structures in the Al-Cu-Fe system. Journal of Physics: Condensed Matter, 8, $2487-2512$.

Rastsvetaeva, R.K., Bolotina, N.B., Sapozhnikov, A.N., Kashaev, A.A., Schönleber, A. and Chapuis, G. (2002) Average structure of cubic lazurite with a three-dimensional incommensurate modulation. Crystallography Reports, 47, 404-407.

Riester, M., Böhm, H. and Petrríček, V. (2000) The commensurately modulated structure of the lock-in phase of synthetic Co-åkermanite, $\mathrm{Ca}_{2} \mathrm{CoSi}_{2} \mathrm{O}_{7}$. Zeitschrift für Kristallographie, 215, 102-109.

Rigault, G. (1999) Il reticolo polare di Bravais e il reticolo reciproco. Atti Scienze Fisiche, Accademia delle Scienze di Torino, 133, 1-8 (in Italian).

Sakamoto, S., Shimobayashi., N. and Kitamura, M. (2003) Incommensurate phase in the kosmochlor-diopside join: A new polymorph of clinopyroxene. American Mineralogist, 88, 1605-1607.

Sanchez-Munoz, L., Nistor, L., Van Tendeloo, G. and Sanz, J. (1998) Modulated structures in $\mathrm{KAlSi}_{3} \mathrm{O}_{8}$ : a study by high resolution electron microscopy and ${ }^{29}$ Si MAS-NMR spectroscopy. Journal of Electron Microscopy, $47,17-28$.

Schaper, A.K., Schosnig, M., Kutoglu, A., Treutmann, W. and Rager, H. (2001) Transition from the 
incommensurately modulated structure to the lock-in phase in Co-åkermanite. Acta Crystallographica, B57, $443-448$.

Schutte, W.J. and de Boer, J.L. (1988) Valence fluctuations in the incommensu;rately modulated structure of calaverite AuTe 2 . Acta Crystallographica, B44, 486-494.

Schutte, W.J. and de Boer, J.L. (1993) Determination of the incommensurately modulated structure of $\mathrm{Cu}_{3-\mathrm{x}} \mathrm{Te}_{2}$. Acta Crystallographica, B49, 398-403.

Seifert, F., Czank, M., Simons, B. and Schmahl, W. (1987) A commensurate-incommensurate phase transition in iron-bearing åkermanite. Physics and Chemistry of Minerals, 14, 26-35.

Shechtman, D., Blech, I., Gratias, D. and Cahn, J.W. (1984) Metallic phase with long-range orientational order and no translational symmetry. Physical Review Letters, 53, 1951-1953.

Smith, H. (1903) Ueber das bemerkenswerthe Problem der Entwicklung der Krystallformen des Calaverit. Zeitschrift für Kristallographie, 37, 209-234.

Steinhardt, P.J. and Bindi, L. (2012) In search of natural quasicrystals. Reports on Progress in Physics, 75 , 092601-092611.

Steurer, W. and Deloudi, S. (2009) Crystallography of Quasicrystals. Concepts, Methods and Structures. Springer, Berlin.

Steurer, W. and Jagodzinski, H. (1988) The incommensurately modulated structure of an andesine $\left(\mathrm{An}_{38}\right)$. Acta Crystallographica, B44, 344-351.

Stokes, H.T., Campbell, B.J. and van Smaalen, S. (2011) Generation of (3+d)-dimensional superspace groups for describing the symmetry of modulated crystalline structures. Acta Crystallographica, A67, 45-55.

Subramanian, R.K., Muntean, L., Norcross, J.A. and Ailion, D.C. (2000) ${ }^{109}$ Ag NMR investigation of atomic motion in the incommensurate and paraelectric phases of proustite $\left(\mathrm{Ag}_{3} \mathrm{AsS}_{3}\right)$. Physical Review, B61, 996-1002.

Tsai, A.P., Inoue, A. and Masumoto, T. (1987) A stable quasicrystal in Al-Cu-Fe system. Japanese Journal of Applied Physics, 26, L1505.

van Aalst, W., den Hollander, J., Peterse, W.J.A.M. and de Wolff, P.M. (1976) The modulated structure of $\gamma-\mathrm{Na}_{2} \mathrm{CO}_{3}$ in a harmonic approximation. Acta Crystallographica, B32, 47-58.

van Heurck, C., van Tendeloo, G. and Amelinckx, S. (1992) The modulated structure in the melilite $\mathrm{Ca}_{2} \mathrm{ZnGe}_{2} \mathrm{O}_{7}$. Physics and Chemistry of Minerals, 18, 441-452.

van Smaalen, S. (2007) Incommensurate Crystallography. Oxford University Press, Oxford, UK.

van Tendeloo, G., Gregoriades, P. and Amelinckx, S. (1983) Electron microscopy studies of modulated structures in (Au,Ag) Te 2 : Part I. Calaverite $\mathrm{AuTe}_{2}$. Journal of Solid State Chemistry, 50, 321-334.

Wiegers, G.A. and Meerschaut, A. (1992) Misfit layer compounds (MS) $)_{\mathrm{n}} \mathrm{S}_{2}(\mathrm{M}=\mathrm{Sn}, \mathrm{Pb}, \mathrm{Bi}$, rare earth metals; $\mathrm{T}$ $=\mathrm{Nb}, \mathrm{Ta}, \mathrm{Ti}, \mathrm{V}, \mathrm{Cr} ; 1.08<\mathrm{n}<1.23)$ : Structures and physical properties. Materials Science Forum, 100-101, $101-172$.

Withers, R.L., Thompson, J.G., Melnitchenko, A. and Palethorpe, S.R. (1998) Cristobalite-related phases in the $\mathrm{NaAlO}_{2}-\mathrm{NaAlSiO}_{4}$ system. II. A commensurately modulated cubic structure. Acta Crystallographica, B54, 547-557.

Withers, R.L., Tabira, Y., Liu, Y. and Höche, T. (2002) A TEM and RUM study of the inherent displacive flexibility of the fresnoite framework structure type. Physics and Chemistry of Minerals, 29, 624-632.

Withers, R.L., Norén, L., Welberry, T.R., Bindi, L., Evain, M. and Menchetti, S. (2008) A composite modulated structure mechanism for $\mathrm{Ag}^{+}$fast ion conduction in pearceite and polybasite mineral solid electrolytes. Solid State Ionics, 179, 2080-2089.

Wolff, P.M. de (1974) The pseudo-symmetry of modulated crystal structures. Acta Crystallographica, A30, $777-785$.

$\mathrm{Xu}$, H. and Veblen, D.R. (1995) Transmission electron microscopy study of optically anisotropic and isotropic haüyne. American Mineralogist, 80, 87-93.

Yamamoto, A., Nakazawa, H., Kitamura, M. and Morimoto, N. (1984) The modulated structure of intermediate plagioclase feldspar $\mathrm{Ca}_{\mathrm{x}} \mathrm{Na}_{1-\mathrm{x}} \mathrm{Al}_{1+\mathrm{x}} \mathrm{Si}_{3-\mathrm{x}} \mathrm{O}_{8}$. Acta Crystallographica, B40, 228-237.

Zubkova, N.V., Pushcharovsky, D.Yu., Ivaldi, G., Ferraris, G., Pekov, I.V. and Chukanov, N.V. (2002) Crystal structure of natrite, $\gamma-\mathrm{Na}_{2} \mathrm{CO}_{3}$. Neues Jahrbuch für Mineralogie Monatshefte, 2, 85-96. 